OPEN ACCESS

Edited by:

Jaewon Ko,

Daegu Gyeongbuk Institute of Science and Technology (DG/ST),

South Korea

Reviewed by:

Kathleen Millen,

Seattle Children's Hospital,

United States

Sandra Blaess,

University of Bonn, Germany

${ }^{*}$ Correspondence:

Albert I. Chen

albert.chen@ntu.edu.sg

Received: 27 May 2017 Accepted: 18 August 2017

Published: 31 August 2017

Citation:

Zainolabidin N, Kamath SP

Thanawalla $A R$ and Chen Al (2017) Distinct Activities of Tfap2A and Tfap2B in the Specification of

GABAergic Interneurons in the Developing Cerebellum.

Front. Mol. Neurosci. 10:281. doi: 10.3389/fnmol.2017.00281

\section{Distinct Activities of Tfap2A and Tfap2B in the Specification of GABAergic Interneurons in the Developing Cerebellum}

\author{
Norliyana Zainolabidin ${ }^{1,2}$, Sandhya P. Kamath ${ }^{1,2}$, Ayesha R. Thanawalla ${ }^{1,2}$ \\ and Albert I. Chen $1,2,3 *$
}

${ }^{1}$ School of Biological Sciences, Nanyang Technological University (NTU), Singapore, Singapore, ${ }^{2}$ School of Life Sciences, University of Warwick, Coventry, United Kingdom, ${ }^{3} A^{*}$ STAR, Institute of Molecular and Cell Biology, Singapore, Singapore

GABAergic inhibitory neurons in the cerebellum are subdivided into Purkinje cells and distinct subtypes of interneurons from the same pool of progenitors, but the determinants of this diversification process are not well defined. To explore the transcriptional regulation of the development of cerebellar inhibitory neurons, we examined the role of Tfap2A and Tfap2B in the specification of GABAergic neuronal subtypes in mice. We show that Tfap2A and Tfap2B are expressed in inhibitory precursors during embryonic development and that their expression persists into adulthood. The onset of their expression follows Ptf1a and Olig2, key determinants of GABAergic neuronal fate in the cerebellum; and, their expression precedes Pax2, an interneuron-specific factor. Tfap2A is expressed by all GABAergic neurons, whereas Tfap2B is selectively expressed by interneurons. Genetic manipulation via in utero electroporation (IUE) reveals that Tfap2B is necessary for interneuron specification and is capable of suppressing the generation of excitatory cells. Tfap2A, but not Tfap2B, is capable of inducing the generation of interneurons when misexpressed in the ventricular neuroepithelium. Together, our results demonstrate that the differential expression of Tfap2A and Tfap2B defines subtypes of GABAergic neurons and plays specific, but complementary roles in the specification of interneurons in the developing cerebellum.

Keywords: Tfap2A, Tfap2B, cerebellum, GABAergic interneurons, transcription factors, development

\section{INTRODUCTION}

The cerebellum plays a critical role in sensory-motor integration and is important for the precise coordination of body, limb and eye movements as well as adaptation and learning of motor skills (Eccles et al., 1967; Thach and Bastian, 2004; Ito, 2006). The ability of the cerebellum to carry out these tasks relies on the specification of distinct classes of cerebellar neurons and the assembly of these neurons into functional circuits during development. Despite consisting of less than 10 percent of all neurons in the cerebellum (Andersen et al., 1992; Korbo et al., 1993), the different subtypes of inhibitory neurons play important roles in cerebellar function by providing feedback and feedforward inhibition (Eccles et al., 1967; Ito, 2006). Cerebellar cortical inhibitory neurons use gamma-aminobutyric acid (GABA) and/or glycine and are made up of four major subtypes: stellate, basket, Purkinje and Golgi cells (Miale and Sidman, 1961; Sillitoe and Joyner, 2007). Stellate and basket cells provide feedforward inhibition to Purkinje cells 
and together regulate motor learning and adaptation as well as fine motor movements (Eccles et al., 1967; De Zeeuw et al., 1998; Wulff et al., 2009; Heiney et al., 2014). Golgi cells, on the other hand, provide feedback inhibition to granule cells to regulate motor coordination and compound movement (Watanabe et al., 1998; D’Angelo et al., 2013). Even though the electrophysiological and morphological properties as well as, to some extent, functional relevance of cerebellar inhibitory neurons have been examined (Palay and Chan-Palay, 1974; Ito, 2006), the molecular mechanisms underlying the diversification of distinct subtypes of cerebellar inhibitory neurons are not well defined.

There is growing evidence that the specification of inhibitory neuronal identity in the cerebellum is controlled by the expression of a set of transcription factors (Pascual et al., 2007; Zordan et al., 2008; Hori and Hoshino, 2012; Hoshino, 2012; Leto and Rossi, 2012). GABAergic neurons of the cerebellar cortex originate from the ventricular neuroepithelium and express basic helix-loop-helix (bHLH) transcription factor Ptfla, which is required for generation of stellate, basket, Purkinje and Golgi cells (Hoshino et al., 2005; Pascual et al., 2007; Yamada et al., 2014). GABAergic projection neurons, the Purkinje cells, are generated by progenitors within the cerebellar ventricular zone (VZ) and require Corl2/Skor2 for differentiation (Minaki et al., 2008; Nakatani et al., 2014). Another bHLH transcription factor, Olig2, is expressed in the embryonic VZ, and some Olig2expressing cells differentiate into Purkinje cells (Seto et al., 2014b; Ju et al., 2016). GABAergic interneurons in the cerebellar cortex, which include stellate, basket and Golgi cells, and in the deep cerebellar nuclei (DCN), are generated in the same region and express Pax 2 as GABAergic interneuron precursors that proliferate in the white matter (WM) layer (Maricich and Herrup, 1999; Leto et al., 2006, 2009; Weisheit et al., 2006). A set of homeobox transcription factors Lhx1/5 is expressed by all GABAergic postmitotic neurons, however, deletion of Lhx1 and Lhx 5 results only in the loss of Purkinje cells, but not GABAergic interneurons (Zhao et al., 2007). Even though a transcriptional program for cerebellar GABAergic neuronal specification is emerging, whether differentially expressed transcription factors have the capability to specify GABAergic interneurons has not yet been identified.

Transcriptome analysis has revealed a number of transcription factors that are regulated by Ptf1a including Lhx1, Lhx5, Corl2, Ngn2 and Pax2 (Borromeo et al., 2014; Russ et al., 2015). Also included in this list are two members of the Transcription Factor AP-2 (Tfap2) family of proteins Tfap2A and Tfap2B (Meredith et al., 2013; Borromeo et al., 2014; Jin et al., 2015; Russ et al., 2015). Tfap2A and Tfap2B have been demonstrated to play important roles for the development of a variety of tissues including the nervous system, kidney, skeleton, skin, limbs and the eye (Schorle et al., 1996; Zhang et al., 1996; Nottoli et al., 1998; West-Mays et al., 1999; Eckert et al., 2005; Seberg et al., 2017). For instance, in the developing nervous system, Tfap2A and Tfap2B are required for the survival of sympathetic and sensory ganglia progenitors (Schmidt et al., 2011). In the developing mouse retina, Tfap $2 A$ and Tfap $2 B$ have been shown to promote the differentiation of GABAergic and glycinergic amacrine cells (Jin et al., 2015). Thus, these two members of the Tfap2 family of transcription factors appear to regulate proliferation and survival of various cell types and may also be involved in the specification of distinct neuronal subtypes during development.

In addition to the sympathetic and sensory ganglia, both Tfap $2 A$ and $T f a p 2 B$ transcripts are expressed in the developing and mature mouse cerebellum (Moser et al., 1995, 1997; Shimada et al., 1999), but the neuronal subtypes within the cerebellum that express these transcription factors have not yet been determined. Moreover, the functional significance of these transcription factors in the specification of cerebellar neuronal subtypes is not known. In this study, we examine the expression pattern and function of Tfap2A and Tfap2B in the mouse cerebellum. First, we assessed the spatial-temporal expression of Tfap2A and Tfap2B across embryonic and postnatal stages. Next, we compared their expression with cell type-specific and developmental markers. Finally, using in utero electroporation (IUE), we explored the functional significance of Tfap2A and Tfap2B during the development of cerebellar GABAergic neuronal subtypes.

\section{MATERIALS AND METHODS}

\section{Animals}

C57BL/6JInv mice were used in this study. All mice were housed and bred in Agency for Science, Technology and Research Biological Resource Centre on a $12 \mathrm{~h}$ light/dark cycle with free access to food and water. This study was carried out in accordance with the recommendations of Agency for Science, Technology and Research Biological Resource Centre. All protocols were approved by the Institute of Animal Care and Use Committee in accordance with the National Advisory Committee for Laboratory Animal Research guidelines.

\section{Immunohistochemistry}

Mice were anesthetized with $2.5 \%$ Avertin $[0.025 \mathrm{~g} / \mathrm{mL}$ 2,2-2 Tribomoethanol (Sigma) in 2-Methyl-2-butanol (Sigma)] prior to perfusion with $0.9 \%$ saline and $4 \%$ paraformaldehyde (Sigma). Early postnatal tissues were then post-fixed for $1 \mathrm{~h}$ while adult tissues were post-fixed overnight in $4 \%$ paraformaldehyde. Pregnant mice were euthanized using carbon dioxide gas chamber and confirmed through cervical dislocation. Embryos were collected in $4 \%$ paraformaldehyde and post-fixed for $30 \mathrm{~min}$. All tissues were preserved overnight in $30 \%$ sucrose (1st BASE) and stored in $-80^{\circ} \mathrm{C}$ in O.C.T compound (Sakura Finetek). All tissues were sectioned at 16-20 $\mu \mathrm{m}$ using a cryostat (ThermoScientific).

Tissue sections were permeabilized with $0.3 \%$ Triton-X (OmniPur) in phosphate buffered saline (PBS; 1st Base) for $10 \mathrm{~min}$ and blocked for $1 \mathrm{~h}$ with $2 \%$ horse serum (Invitrogen) and $0.1 \%$ Triton-X in PBS. The sections were then incubated with primary antibodies overnight in $4^{\circ} \mathrm{C}$. On the following day, the tissues were washed with $0.1 \%$ Triton-X in PBS for 3 min three times and incubated with secondary antibodies for $1 \mathrm{~h}$. Tissue sections were again washed and stained with DAPI before being mounted with a coverslip. 
Primary antibodies used were as follows: rabbit anti-Tfap2B (1:10,000; gift from T. Jessell, Columbia University), rabbit anti-Ptfla (1:1000; gift from C. Wright, Vanderbilt University), rabbit anti-Tfap2A (1:500; Santa Cruz Bio Technology), goat anti-Pax6 (1:500; Santa Cruz Bio Technology) and mouse anti-Pax2 (1:500; Santa Cruz Bio Technology), mouse anti-Tfap2A (2 $\mu \mathrm{g} / \mathrm{mL}$; developed by $\mathrm{T}$. Williams, Developmental Studies Hybridoma Bank) and mouse antiLhx1/5 (2 $\mu \mathrm{g} / \mathrm{mL}$; developed by T. Jessell, Developmental Studies Hybridoma Bank), goat anti-Olig2 (1:250; R\&D), mouse anti-Calbindin (1:5000; Swant) and goat anti-Parvalbumin (1:5000; Swant), rat anti-green fluorescent protein (GFP) (1:1000; Nacalai Tesque) and rat anti-RFP (1:500; Chromotek). Secondary antibodies used were as follows: Donkey anti-Rabbit Alexa Fluor 488, Donkey anti-Rabbit Alexa Fluor 647, Donkey anti-Goat Alexa Fluor 555, Donkey anti-Mouse Alexa Fluor 647, Donkey anti-Rat Alexa Fluor 488 and Donkey anti-Rat Alexa Fluor 555 (1:1000; Molecular Probes).

\section{Generation of Expression Constructs}

For overexpression (OE) studies, pCDH lentivector (pEF1MCS-IRES-RFP) was used (System Bioscience, \#CD531A-2). Individual transfer vectors containing open reading frames of Tfap $2 A$ and Tfap $2 B$ (GeneArt Invitrogen) were sub-cloned into multiple cloning site (MCS) of pCDH lentivector. Plasmids were digested with $\mathrm{Xba \textrm {I }}$ and NotI (New England Biolabs) restriction enzymes and isolated on $1 \%$ agarose gel. Digested plasmids were ligated using T7 DNA ligase (New England Biolabs) for $20-22 \mathrm{~h}$ at $16^{\circ} \mathrm{C}$. For knockdown studies, pLL3.7 lentivector (pU6-MCS-CMV-GFP; Addgene) was used to express target short hairpin RNA (shRNA) under U6 promoter and GFP reporter controlled by cytomegalovirus (CMV) promoter. DNA oligonucleotides which will be transcribed into shRNA were designed using Invitrogen BLOCK-iT $\mathrm{TM}_{\mathrm{TM}} \mathrm{RNAi}$ Designer. It comprised of XhoI overhang ( $5^{\prime}$ TCGA $3^{\prime}$ ) on the $5^{\prime}$ end of the antisense strand and a short hairpin loop $\left(5^{\prime}\right.$ TTCAAGAGA $\left.3^{\prime}\right)$. Targeting sequence used for scramble is 5' TGCCCTACCACCGAGGTCAA 3', for Tfap2A knockdown is $5^{\prime}$ TGACAACATTCCGATCCCAATG $3^{\prime}$ and for Tfap2B knockdown is $5^{\prime}$ TGCATGGACAAGATGTTCTTGA $3^{\prime}$. Forty micromolar of sense and antisense oligonucleotides diluted in 1X T4 DNA ligase buffer (New England Biolabs) were annealed by boiling at $100^{\circ} \mathrm{C}$ for $10 \mathrm{~min}$ and cooled to room temperature. Subsequently, both the pLL3.7 and annealed oligonucleotides were digested, separately, with $\mathrm{XhoI}$ and $\mathrm{HpaI}$ (New England Biolabs). Ligation was carried out similar to the $\mathrm{OE}$ construct. Cloned vectors were sequenced by Institute of Molecular and Cellular Biology, DNA Sequencing Facility.

\section{Western Blot}

Human embryonic kidney 293T (HEK-293T) cells were seeded at a density of 500,000 cells per well in a 6-well tissue culture plate a day before transfection. OPTI-MEM reduced serum media (Gibco) was used to dilute $1 \mu \mathrm{g}$ of DNA as well as Lipofectamine 2000 reagent (Invitrogen). Lipid-DNA mixture was introduced into the cells and was incubated for $48 \mathrm{~h}$ before protein isolation.
Cells were washed once with PBS before proteins were isolated using M-PER mammalian protein extraction reagent (Pierce) which is supplemented with phosphatase inhibitor tablet (Pierce) and protease inhibitor cocktail (Sigma). Proteins were subsequently quantified via colorimetric assay (Bio-Rad) according to manufacturer's protocol. Twenty microgram of proteins were used for fractionation by SDS-PAGE and transferred to a PVDF membrane using iBlot ${ }^{\circledR}$ Dry Blotting System (Invitrogen). After incubation with $2 \%$ Bovine Serum Albumin (BSA) diluted in TBS-T (10 mM Tris [pH 8.0], $150 \mathrm{mM}$ $\mathrm{NaCl}, 0.5 \%$ Tween 20) for an hour, this blocking buffer was decanted and primary antibodies were incubated overnight at $4^{\circ} \mathrm{C}$.

The primary antibodies used were as follows: rabbit anti-Tfap2A (1:500; Santa Cruz Bio Technology), rabbit anti-Tfap2B (1:500; Santa Cruz Bio Technology), and mouse anti-GAPDH $(0.05 \mu \mathrm{g} / \mathrm{mL}$; Sigma). On the next day, membranes were washed with TBS-T thrice, for $10 \mathrm{~min}$ each before being incubated with appropriate secondary antibodies. The secondary antibodies used were diluted in blocking buffer as follows: anti-mouse $\operatorname{IgG}$ fragment-peroxidase antibody produced in goat (1:3000; Sigma) and anti-rabbit IgG fragment-peroxidase antibody produced in goat (1:3000; Sigma). Membrane was washed again, similarly, before being developed with the ECL system (Cell Signaling) according to manufacturer's protocol.

\section{In Utero Electroporation}

C57BL/6J pregnant mice were anesthetized with $2 \%$ isoflurane throughout the procedure and were kept warm using a homeothermic blanket. Hair on the abdomen area was shaved and skin cleaned with cotton swabs soaked in $70 \%$ ethanol. A small incision $(5-10 \mathrm{~mm}$ ) on the abdomen through the midline was done and gauze moistened with $42^{\circ} \mathrm{C} 0.9 \%$ saline was placed around the incision. Another incision on the muscle was made and both of the uterine horns were carefully placed on the gauze. From time to time, the exposed embryos were moistened with warm saline. $2-5 \mu \mathrm{L}$ of purified plasmids $(1 \mu \mathrm{g} / \mu \mathrm{L})$ with Fastgreen Dye $(0.1 \mathrm{mg} / \mathrm{mL})$ were delivered into the fourth ventricle using a glass capillary. Electrodes were positioned in between the ventricles and five pulses of $250 \mathrm{mV}$ for $50 \mathrm{~ms}$ each, were delivered. Uterine horns were returned into the peritoneal cavity and warm saline was added before the lining of cavity and the skin was sutured. Mice were given Meloxicam for post-operative pain management.

\section{Image and Cell Count Analysis}

Confocal images from immunohistochemistry were captured using Zeiss LSM-710 Confocal Microscope System (Axio Imager Z2 Stand) on ZEN2011. All images were processed with ImageJ (National Institute of Health).

For the Tfap2-Pax 2 cell count analysis, two sagittal sections were obtained from the vermis region of each of the three brains and cells were counted, Using ImageJ, specific regions of interest were manually drawn around all nuclei positive for Tfap2A, Tfap2B and Pax2 and were subsequently scored. Immuno-positive neurons were then grouped and percentages were calculated. 
Analysis for in utero electroporation experiments was assessed by counting all, transfected cells in the WM layer from multiple sagittal sections (approximately 10-25 sections, 100-500 cells) were counted for three brains. Cells were scored for the respective molecular markers and percentages were calculated. Experimental groups were compared against control groups.

\section{Statistical Analysis}

A non-parametric student's $t$-test was carried out in all the experiments that require statistical analysis. Data represents mean \pm SEM. All data was analyzed with GraphPad Prism 6. The statistical data are described in each figure legend.

\section{RESULTS}

\section{Analysis of the Spatial Expression Pattern of Tfap2A and Tfap2B in the Developing and Mature Cerebellum}

In order to uncover the involvement of Tfap2 transcription factors in the development of GABAergic neurons and determine their functional relevance, we analyzed the expression of Tfap $2 \mathrm{~A}$ and Tfap2B in the developing mouse cerebellum. We first assessed whether Tfap2A and Tfap2B are expressed in the rhombic lip (RL) and the intermediate domain of rhombomere (r)1, where the first cerebellar neurons such as glutamatergic DCN neurons and GABAergic Purkinje cells are generated at embryonic day (E) 10.5 (Hoshino et al., 2005; Machold and Fishell, 2005; Wang et al., 2005). The expression of both Tfap2A and Tfap2B was not detected in either of these regions at this stage (Figures 1A,B). At E12.5, we observed expression of Tfap2A and Tfap2B in the WM layer of the cerebellum, located superior to the $\mathrm{VZ}$ where GABAergic neurons are produced (Figures 1C,D; Hoshino et al., 2005). The expression of Tfap2B appears to be more widespread than Tfap $2 \mathrm{~A}$ at this stage which may reflect the expression of Tfap2B in non-cerebellar cell types (Figures 1C-F). Since GABAergic neurons transit in the WM before they reassemble to specific layers in the cerebellar cortex (Zhang and Goldman, 1996; Maricich and Herrup, 1999; Leto et al., 2009), our results suggest that Tfap $2 \mathrm{~A}^{+}$and $\mathrm{Tfap}_{2} \mathrm{~B}^{+}$cells partake a GABAergic neuron migratory pathway and are expressed by GABAergic precursors in the embryonic cerebellum.

To determine whether the expression of Tfap $2 \mathrm{~A}$ and Tfap $2 \mathrm{~B}$ is maintained during late embryogenesis through postnatal stages, we analyzed their expression in perinatal and postnatal cerebellar tissues. The spatial expression pattern of Tfap2A and Tfap2B at E15.5 and P0 supports our earlier observations that Tfap2A and Tfap2B are expressed by GABAergic neurons (Figures 1E-H). In $\mathrm{P} 10$ and adult cerebellum, we found Tfap $2 \mathrm{~A}^{+}$neurons in the molecular layer (ML), Purkinje cell layer (PCL) and internal granular layer (IGL; Figures 1I,K). Tfap2A is expressed by a subset of calbindin ${ }^{+}$Purkinje cells in the developing cerebellum suggesting that it could mark early-onset Purkinje cell clusters which disperse after birth (Figure 1G, Supplementary Figures S1A-D). However, colocalization analysis in the coronal orientation in the adult

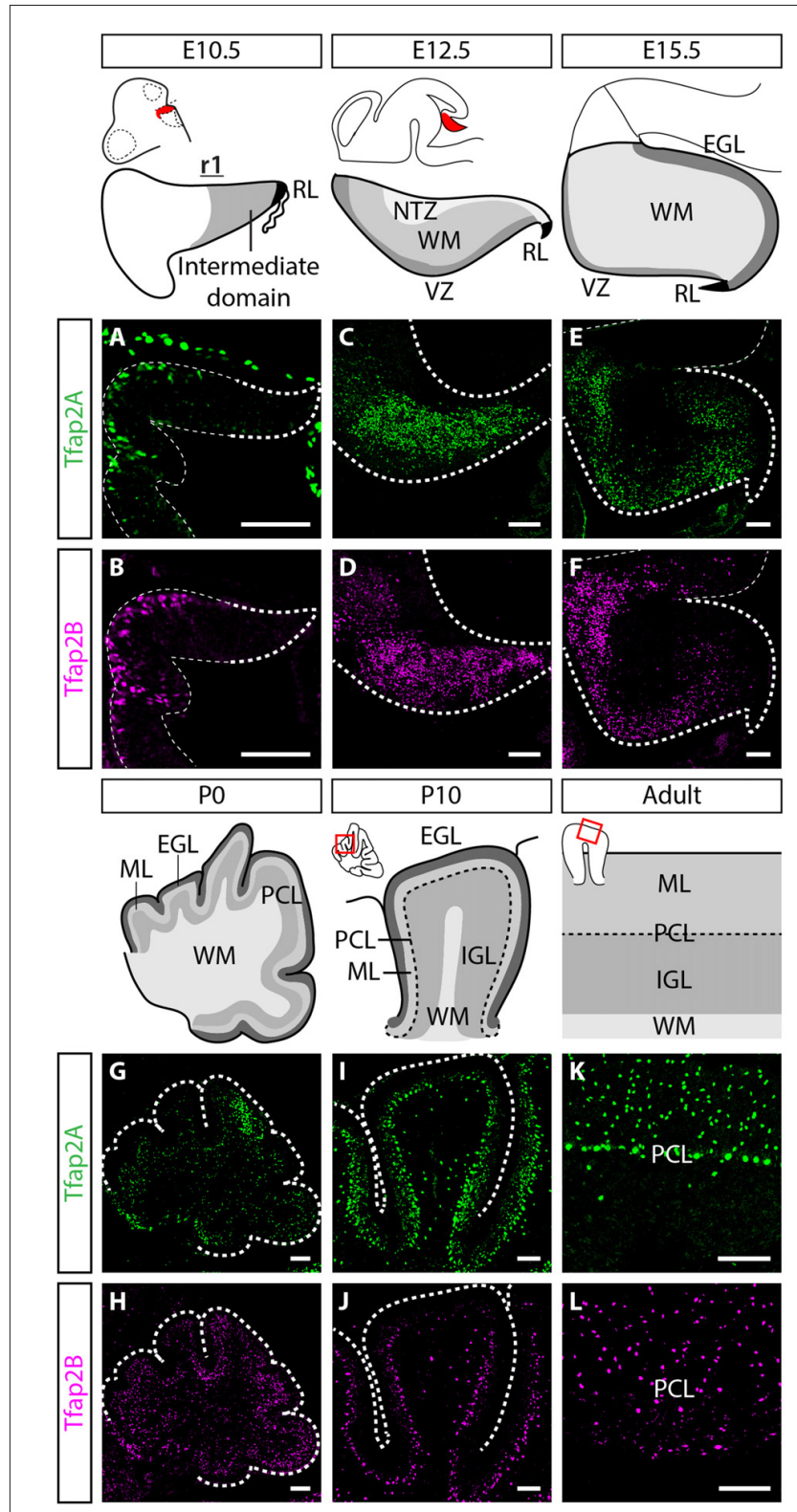

FIGURE 1 | Spatiotemporal expression pattern of Tfap2A and Tfap2B in the cerebellum. (A,B) Expression of both Tfap2A (green, $\mathbf{A}$ ) and Tfap2B (magenta, B) is not detected in the cerebellar derivatives in $\mathrm{r} 1$ at $\mathrm{E} 10.5$. (C-H) Expression of Tfap2A and Tfap2B is detected in the underlying WM at E12.5 (C,D) and E15.5 (E,F) where inhibitory neurons transit after exiting the VZ. At early postnatal stages, P0 and P10, Tfap2A, but not Tfap2B, is expressed in the PCL (G,I). In addition, by P10 both Tfap2 $A^{+}$(I) and Tfap2B ${ }^{+}$ cells $(\mathbf{J})$ have entered the lower half of the $M L$ and the IGL. $(\mathbf{K}, \mathbf{L})$ In the mature cerebellum at P150, Tfap2A expression (K) is detected in the ML, PCL and IGL whereas Tfap2B expression (L) is restricted to the ML and IGL. Analysis performed on cerebellar vermal region of sagittal sections. Abbreviations: EGL, external germinal layer; IGL, internal granular layer; ML, molecular layer; NTZ, nuclear transitory zone; PCL, Purkinje cell layer; RL, rhombic lip; $r 1$, rhombomere 1; VZ, ventricular zone; WM, white matter. Scale bar $=100 \mu \mathrm{m}$.

cerebellum revealed that Tfap2A is uniformly expressed in parvalbumin $^{+}$Purkinje cells (Supplementary Figures S1E-H). These results indicate Tfap2A is expressed in a subset of Purkinje 


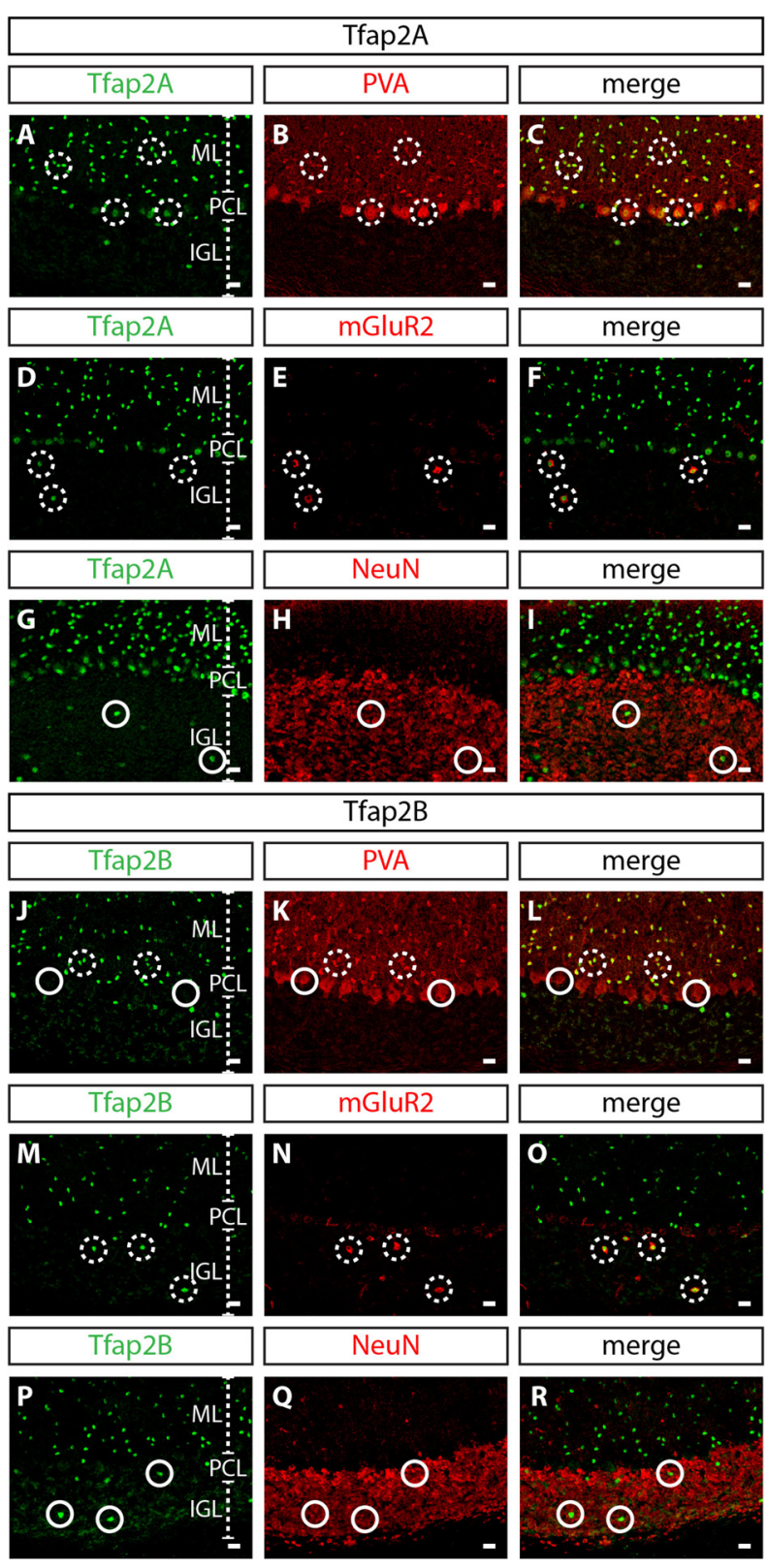

FIGURE 2 | Expression of Tfap2A and Tfap2B is restricted to GABAergic neuronal subtypes in the adult cerebellum. (A-R) Analysis of the expression of Tfap2A and Tfap2B with cell type-specific molecular markers in the adult cerebellar cortex. At P60, Tfap2A (green) is coexpressed with PVA (red) in the $\mathrm{ML}$ and PCL (A-C) and with mGluR2 (red) in the IGL (D-F). Tfap2B (green) is coexpressed with PVA (red) only observed in the ML (J-L) and with mGluR2 (red) in the IGL (M-O). No Tfap2A (G-I) or Tfap2B (P-R) expression (green) is detected in $\mathrm{NeuN}^{+}$granule cells (red) in the IGL. Analysis performed on cerebellar vermal region of sagittal sections. Broken circles indicate cells with colocalized expression, continuous circles indicate no colocalization. Abbreviations: IGL, internal granular layer; ML, molecular layer; PCL, Purkinje cell layer. Scale bar $=10 \mu \mathrm{m}$.

cells during development, but is expressed by all Purkinje cells in the adult cerebellum. Tfap $2 \mathrm{~B}^{+}$neurons, on the other hand, are only detected in the ML and IGL (Figures 1J,L).
Thus, due to their overlapping expression pattern, we compared the expression of Tfap $2 \mathrm{~A}$ and Tfap $2 \mathrm{~B}$ with cell-type specific molecular markers in the adult cerebellum. We show that Tfap2A is found in stellate, basket and Purkinje cells, which are all labeled by parvalbumin (Figures $2 \mathrm{~A}-\mathbf{C}$ ). Tfap2A is also found in Golgi cells, which are labeled by mGluR2 (Figures 2D-F). Tfap2B, on the other hand, is expressed only by stellate, basket and Golgi cells (Figures 2J-O). Neither Tfap2A nor Tfap2B is observed in $\mathrm{NeuN}^{+}$granule cells (Figures 2G-I,P-R). Additionally, analysis of the DCN also shows that Tfap2A, but not Tfap2B, labels small GABAergic neurons in all three nuclei (Supplementary Figure S2). Thus, analysis of the temporal and spatial expression pattern of Tfap2A and Tfap2B indicates that they are expressed as early as E12.5 in the cerebellum when GABAergic neurons are produced, and that their expression persists into adulthood.

\section{Molecular Distinctions between Tfap2A ${ }^{+}$ and Tfap2B ${ }^{+}$Neurons in the Developing Cerebellum}

To define the identity of $\mathrm{Tfap} \mathrm{A}^{+}$and $\mathrm{Tfap}^{+} \mathrm{B}^{+}$cells in the early developing cerebellum, we differentiated regions of the embryonic cerebellum with relevant molecular markers of GABAergic lineage at E12.5. The VZ can be demarcated by Ptfla, a transcription factor responsible for differentiation of neural precursors into GABAergic neuron precursors (Hoshino et al., 2005; Yamada et al., 2014). The cerebellar VZ can also be marked by two other transcription factors namely Olig2 and Pax2 which contribute to Purkinje cell and interneuron development (Seto et al., 2014a,b; Ju et al., 2016). We observed an overlap in the expression of Ptf1a and Olig2 which demonstrates that Olig2expressing cells are GABAergic precursors (Figures $3 \mathrm{~A}-\mathbf{C}$ ). Therefore, Tfap2A and Tfap2B are primarily expressed by cells in the $\mathrm{VZ}$ and $\mathrm{WM}$ (Figures 3D-F). However, we observed some Tfap2 ${ }^{+}$cells which do not express Tfap2A in the VZ (Figures 3D-F). Thus, the expression pattern at E12.5 indicates that $\mathrm{Tfap}_{2} \mathrm{~A}^{+}$cells consist of a subset of $\mathrm{Tfap}^{2} \mathrm{~B}^{+}$cells and suggests that their expression defines distinct neuronal subpopulations.

To determine whether Tfap2A and Tfap2B are expressed by mitotic or postmitotic GABAergic neurons, we assessed whether these cells express transcription factors Lhx1/5 (postmitotic), Olig2 and Pax2 (both mitotic and postmitotic; Maricich and Herrup, 1999; Chizhikov et al., 2006; Morales and Hatten, 2006; Zhao et al., 2007). In the VZ, most Tfap $2 \mathrm{~A}^{+}$cells express both Olig2 and Lhx1/5, indicating that these cells in the $\mathrm{VZ}$ are early postmitotic GABAergic neurons (Figures 3G-J). In contrast, some Tfap2 ${ }^{+}$cells in the VZ express Olig2 while others express both Olig2 and Lhx1/5 (Figures 3K-N). Thus, 50\% of Olig2-expressing cells express Tfap 2 A while $\sim 100 \%$ of Olig2expressing cells express Tfap2B (Figures 3G-N; data not shown). Together, these numbers suggest that $\mathrm{Tfap}_{2} \mathrm{~B}^{+}$cells in the VZ consist of both mitotic as well as early postmitotic GABAergic cells. Tfap $2 \mathrm{~A}^{+}$and $\mathrm{Tfap}^{2} \mathrm{~B}^{+}$cells in the WM only express Lhx1/5 indicating that they are postmitotic GABAergic neurons (Figures 3G-N). These results show that Tfap $2 \mathrm{~A}^{+}$and Tfap $2 \mathrm{~B}^{+}$ 


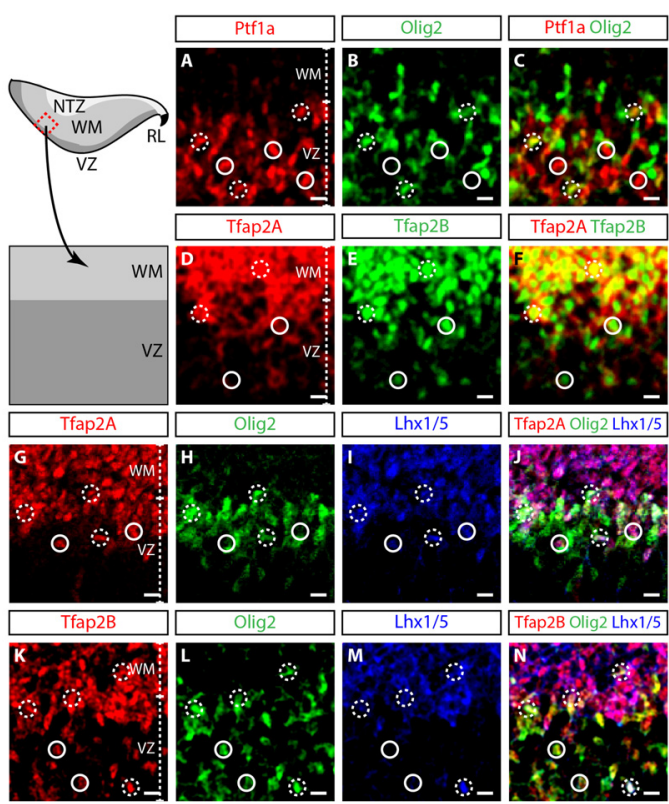

FIGURE 3 | Tfap2A and Tfap2B are expressed in GABAergic precursors. (A-C) At E12.5, Ptf1a (red, A) and Olig2 (green, B) expression is predominantly localized in the VZ. Overlapping Ptf1a and Olig2 expression is observed in the intermediary region of the VZ (broken circle). (D-F) Tfap2A (red, D) and Tfap2B (green, E) are coexpressed in the VZ and WM. (G-J) Expression of Tfap2A (red) colocalizes with Olig2 (green) and Lhx1/5 (blue) in the VZ (broken circle). However, not all Olig2-expressing cells in the VZ express Tfap2A (continuous circle, J). (K-N) The expression of Tfap2B also colocalizes with Olig2 and Lhx1/5 (broken circle). In addition, all Olig2-expressing cells express Tfap2B (circle). Analysis performed on cerebellar vermal region of sagittal sections. Broken circles indicate cells with colocalized expression, continuous circles indicate no colocalization. Abbreviations: VZ, ventricular zone; WM, white matter. Scale bar $=10 \mu \mathrm{m}$.

cells at E12.5 are GABAergic, and Tfap2A labels postmitotic cells while Tfap2B labels both mitotic and postmitotic cells in the VZ.

\section{Hierarchical Expression of Ptf1a, Tfap2A/B and Pax2 in the Developing Cerebellum}

The expression of Tfap2A and Tfap2B is not observed in the $\mathrm{VZ}$ delineated by Ptfla, but is expressed together with Olig2, suggesting Ptf1a expression precedes Tfap2A and Tfap2B (Figures 3G-N; Hoshino et al., 2005). In addition, Tfap $2 \mathrm{~A}^{+}$and Tfap2 $\mathrm{B}^{+}$cells also overlap with Pax2 indicating that these cells identify for interneuron precursors (Supplementary Figure S3). To determine the temporal expression pattern of Tfap $2 \mathrm{~A}$ and Tfap2B in relation to cerebellar neuronal markers, we compared their expression at E15.5 and E18.5 with Pax2 and ROR $\alpha$, molecular markers for GABAergic interneuron precursors and postmitotic Purkinje cells, respectively (Nakagawa et al., 1997; Maricich and Herrup, 1999; Ino, 2004; Weisheit et al., 2006). Purkinje cells are specified in the VZ while interneurons diversifies later in the WM (Miale and Sidman, 1961; Palay and Chan-Palay, 1974; Leto et al., 2006, 2009). At E15.5, $\mathrm{ROR} \alpha$ expression is localized in the dorsal region and spreads under the external germinal layer (EGL; Figures 4A,C,D,F). On the other hand, Pax2 expression is more limited to the

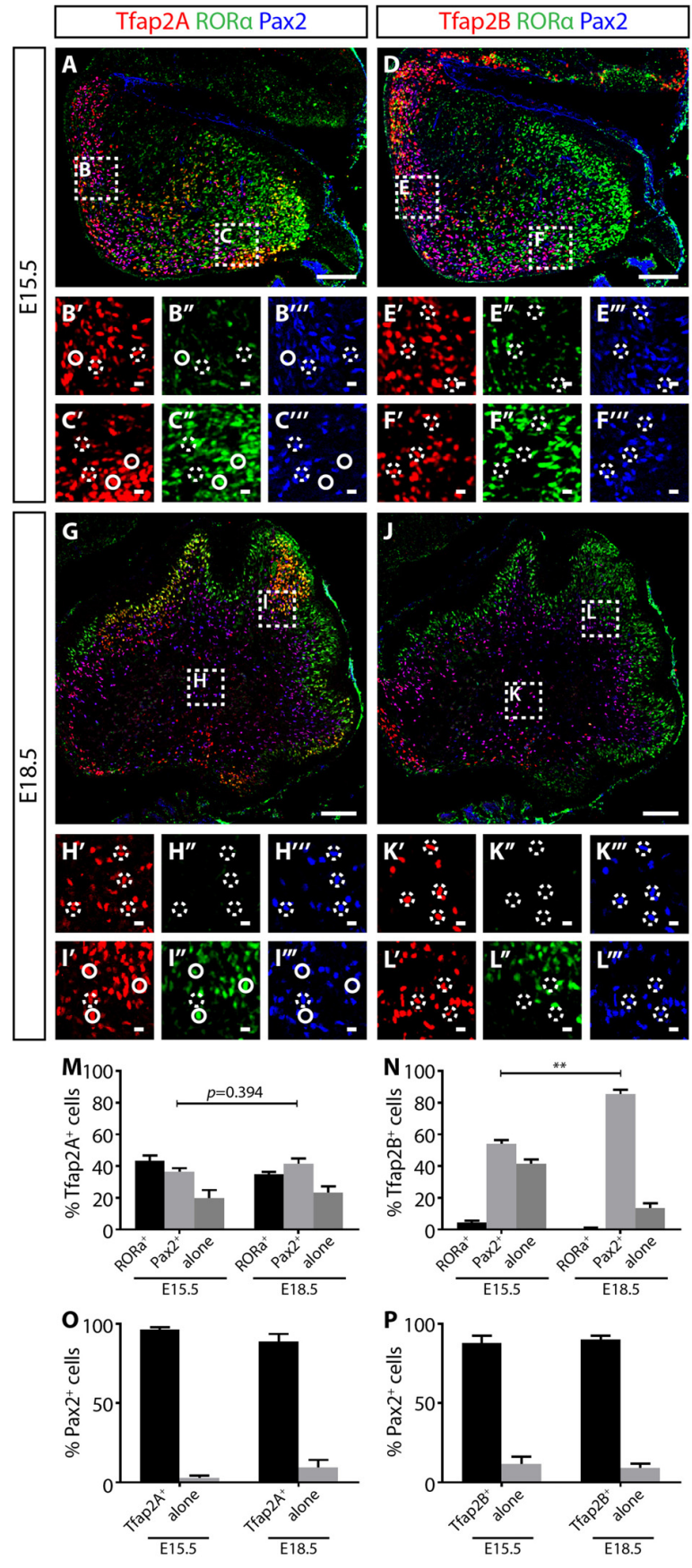

FIGURE 4 | Tfap2A and Tfap2B expression precedes Pax2 in the developing cerebellum. (A-F'") At E15.5, Tfap2A is expressed by a subset of ROR $\alpha^{+}$ Purkinje cells (green) and Pax2 ${ }^{+}$interneurons (blue) $\mathbf{( A )}$ while Tfap2B is expressed by only Pax ${ }^{+}$interneurons (D). Expression of ROR $\alpha$ is localized mostly at the dorsal region of the cerebellum $\left(\mathbf{B}^{\prime}-\mathbf{B}^{\prime \prime \prime}, \mathbf{E}^{\prime}-\mathbf{E}^{\prime \prime \prime}\right)$ while the expression of Pax2 is localized near the ventral region $\left(\mathbf{C}^{\prime}-\mathbf{C}^{\prime \prime \prime}, \mathbf{F}^{\prime}-\mathbf{F}^{\prime \prime \prime}\right)$. (G-L'") At E18.5, the same Tfap2A+ and Tfap2B ${ }^{+}$subpopulations persist, but with different distributions. (M) Quantification of three Tfap2 $\mathrm{A}^{+}$neuronal subpopulations (E15.5: Tfap2 $A^{+} / R_{0 R} \alpha^{+}=43 \pm 3 \%$,

Tfap2A ${ }^{+} / \mathrm{Pax}^{+}=37 \pm 2 \%$, Tfap2 $\mathrm{A}^{+}$-alone $=20 \pm 5 \%$; E18.5:

$\mathrm{Tfap} \mathrm{A}^{+} / \mathrm{ROR}^{+}=35 \pm 1 \%$, Tfap2A ${ }^{+} / \mathrm{Pax}^{+}=42 \pm 3 \%$,

Tfap2 $^{+}$-alone $=23 \pm 4 \%$ ). (N) Quantification of two Tfap2B ${ }^{+}$neuronal 


\section{FIGURE 4 | Continued}

subpopulations (E15.5: $\mathrm{Tfap}^{2} \mathrm{~B}^{+} / \mathrm{Pax}^{+}=54 \pm 3 \%$,

Tfap2B ${ }^{+}$-alone $=42 \pm 3 \%$; E18.5: Tfap2 $^{+} / \mathrm{Pax}^{+}=86 \pm 3 \%$,

Tfap2 $\mathrm{B}^{+}$-alone $\left.=14 \pm 3 \%\right)$. (O,P) Analysis of $\mathrm{Pax}^{+}$neuronal population indicates that most Pax2 ${ }^{+}$interneurons express Tfap2A (E15.5: $97 \pm 1 \%$, E18.5: $89 \pm 4 \%$ ) and Tfap2B (E15.5: $88 \pm 4 \%$, E18.5: $90 \pm 2 \%$ ) at both E15.5 and E18.5. Analysis performed on cerebellar vermal region of sagittal sections. Continuous circles indicate colocalization of Tfap2 with ROR $\alpha$ and broken circles indicate colocalization of Tfap2 with Pax2. Values represent mean $\pm \mathrm{SEM}, n=3$ mice, 2 sections per mouse, ${ }^{*} p \leq 0.05,{ }^{* *} p \leq 0.01$. Scale bar $=100 \mu \mathrm{m}$ (A,D,G,J), $10 \mu \mathrm{m}$ (cropped images).

ventral region (Figures 4A,B,D,E). In E18.5 cerebellum, ROR $\alpha$ is expressed in the PCL while Pax2 expression is restricted to the WM (Figures $\mathbf{4 H}, \mathbf{I}, \mathbf{K}, \mathbf{L}$ ). This pattern of expression defines the migrating status of Purkinje cells and GABAergic interneuron precursors from the $\mathrm{VZ}$ to the $\mathrm{WM}$ and finally to the cerebellar cortex providing us with the basis for analysis of Tfap $2 \mathrm{~A}$ and Tfap2B expression during this process.

At both E15.5 and E18.5, we identified three Tfap2A subpopulations $\left(\mathrm{Tfap} 2 \mathrm{~A}^{+} / \mathrm{Pax} 2^{+}, \quad\right.$ Tfap $2 \mathrm{~A}^{+} / \mathrm{ROR} \alpha^{+}$and Tfap $2 \mathrm{~A}^{+}$-alone) consisting of Purkinje cells and interneurons (Figures 4A-C,G-I). At these stages, we also identified two Tfap2B subpopulations (Tfap $2 \mathrm{~B}^{+} / \mathrm{Pax}^{+}$and $\mathrm{Tfap}^{+} \mathrm{B}^{+}$alone) made up of only interneurons, but not Purkinje cells, consistent with the lack of Tfap2B expression in Purkinje cells in the adult cerebellum (Figures 4D-F,J-L, see also Figures 2J-L). To examine the expression dynamics of Tfap2A and Tfap2B subpopulations, we analyzed sagittal sections of the cerebellum and examined the changes in the distribution of each subpopulation. Between E15.5 to E18.5, we detected a $5 \%$ increase in $\mathrm{Tfap}_{2} \mathrm{~A}^{+} / \mathrm{Pax} 2^{+}$cells and a $3 \%$ increase in cells expressing only Tfap $2 \mathrm{~A}$, although these changes are not statistically significant ( $p=0.394$; Figure $4 \mathrm{M}$ ). We observed an increase in Tfap $2 \mathrm{~B}^{+} / \mathrm{Pax} 2^{+}$cells from $54 \%$ to $86 \%$ and a decrease in cells expressing only Tfap $2 \mathrm{~B}$ from $42 \%$ to $14 \%$ ( $p \leq 0.01$; Figure $4 \mathbf{N}$ ). These changes suggests that cells previously expressing only Tfap2A or Tfap2B are now also expressing Pax2, and that, perhaps, Tfap $2 \mathrm{~A}^{+}$and $\mathrm{Tfap}^{2} \mathrm{~B}^{+}$cells become GABAergic interneurons expressing Pax2 as they mature in the WM. Analysis of changes in Pax2 expression between E15.8 and E18.5 revealed that $\sim 92 \%$ of Pax2 ${ }^{+}$cells express Tfap2A and $\sim 89 \%$ express Tfap $2 B$, indicating majority of Pax $2^{+}$interneurons express Tfap2A and Tfap2B (Figures 4O,P). Together, these results provide evidence that the expression of Tfap2A and Tfap2B precedes the expression of Pax2 and raise the possibility that Tfap $2 \mathrm{~A}$ and Tfap $2 \mathrm{~B}$ regulate the expression of Pax2.

\section{Manipulation of the Expression of Tfap2A and Tfap2B in GABAergic Precursors}

To investigate the functional relevance of Tfap $2 \mathrm{~A}$ and Tfap $2 \mathrm{~B}$ during the development of GABAergic neuronal subtypes, we set out to manipulate the expression of Tfap2A and Tfap2B via IUE. We first generated knockdown constructs containing short hairpin RNA (shRNA) under mouse U6 promoter and GFP under $C M V$ promoter (pU6-shRNA-CMV-GFP; Figure 5A).
We also generated cDNA constructs expressing either Tfap $2 A$ or $T f a p 2 B$ and red fluorescent protein (RFP) separated by Internal Ribosomal Entry Site (IRES) sequence under the elongation factor 1 (EF1) promoter ( $\mathrm{pEF1-cDNA-IRES-RFP;}$ Figure 5B). To determine the efficiency and specificity of these constructs, knockdown and OE plasmids were co-transfected into HEK-293T cells which do not normally express either of these transcription factors. Following that, western blot was carried out to identify the most efficient and specific shRNA that targets the respective member of Tfap2. We found that pU6-2Ash2 and pU6-2Bsh2 to be most efficient and specific in targeting Tfap2A and Tfap2B expression, respectively, so they were subsequently used for in vivo experiments (Figures 5C,D).

For IUE experiments, plasmid constructs were delivered into the fourth ventricle (4v) of E12.5 wild-type (WT) embryos. Cells lining the $4 \mathrm{v}$, which includes the $\mathrm{VZ}$ and $\mathrm{RL}$ with sparse Tfap2A and Tfap2B expression, were transfected via electroporation (Figures 5E,F, Supplementary Figure S4). After 3 days, transfected neurons from the VZ migrate anteriorly into the WM while neurons originating from the RL migrate tangentially over the cerebellar surface before descending into the WM (Figure 5G). Therefore, we analyzed the identity of transfected cells which have migrated into the WM. In control or scrambled experiments, $\sim 33 \%$ of $\mathrm{GFP}^{+}$cells express Tfap $2 \mathrm{~A}$ while $\sim 22 \%$ express Tfap2B (Figures $5 \mathbf{H}, \mathbf{J}, \mathbf{N}, \mathbf{P}$ ). In knockdown experiments, Tfap $2 \mathrm{~A}$ knockdown reduces the percentage of transfected cells expressing Tfap $2 \mathrm{~A}$ by 10 -fold while Tfap2B knockdown reduces the percentage of transfected cells expressing Tfap $2 \mathrm{~B}$ by 20 -fold (Figures $\mathbf{5 H}-\mathbf{J}, \mathbf{N}-\mathbf{P}$ ). In the OE experiments, we observed a $\sim$ three-fold and five-fold increase in the number of transfected cells expressing Tfap2A and Tfap2B, respectively (Figures $\mathbf{5 K}-\mathbf{M}, \mathbf{Q}-\mathbf{S}$ ). This strategy provides means to manipulate Tfap2 expression in vivo through suppression and induction of their expression.

\section{Consequences of Manipulating Tfap2A and Tfap2B Expression on Specification of GABAergic Interneurons}

Ptfla is a major determinant of specification of GABAergic neuronal fate (Pascual et al., 2007; Hori and Hoshino, 2012; Yamada et al., 2014), but determinants of GABAergic interneurons vs. GABAergic projection neurons are limited. To assess the capability of Tfap $2 \mathrm{~A}$ and Tfap2B in directing the specification of GABAergic neuronal subtypes, we analyzed consequences of misexpressing each transcription factor on the expression of neuronal markers, Pax2, Pax6 and CBP which correspond to GABAergic interneurons, glutamatergic neurons and Purkinje cells, respectively. We first examined whether misexpression of Tfap2A or Tfap2B is sufficient to regulate Pax2 expression. We did not observe any changes in the number of $\mathrm{Pax} 2^{+}$interneurons in Tfap2B-misexpressed cells compared to control (Figures 6A,C,D). Interestingly, we observed a $\sim 16 \%$ decrease in the number of $\mathrm{Pax}^{+}$excitatory cells within Tfap2Bmisexpressed cells compared to control (Figures 6E,G,H). Next, we assessed consequences of misexpressing Tfap2A. Despite the inability of Tfap2B to change the number of $\mathrm{Pax}^{+}$ 

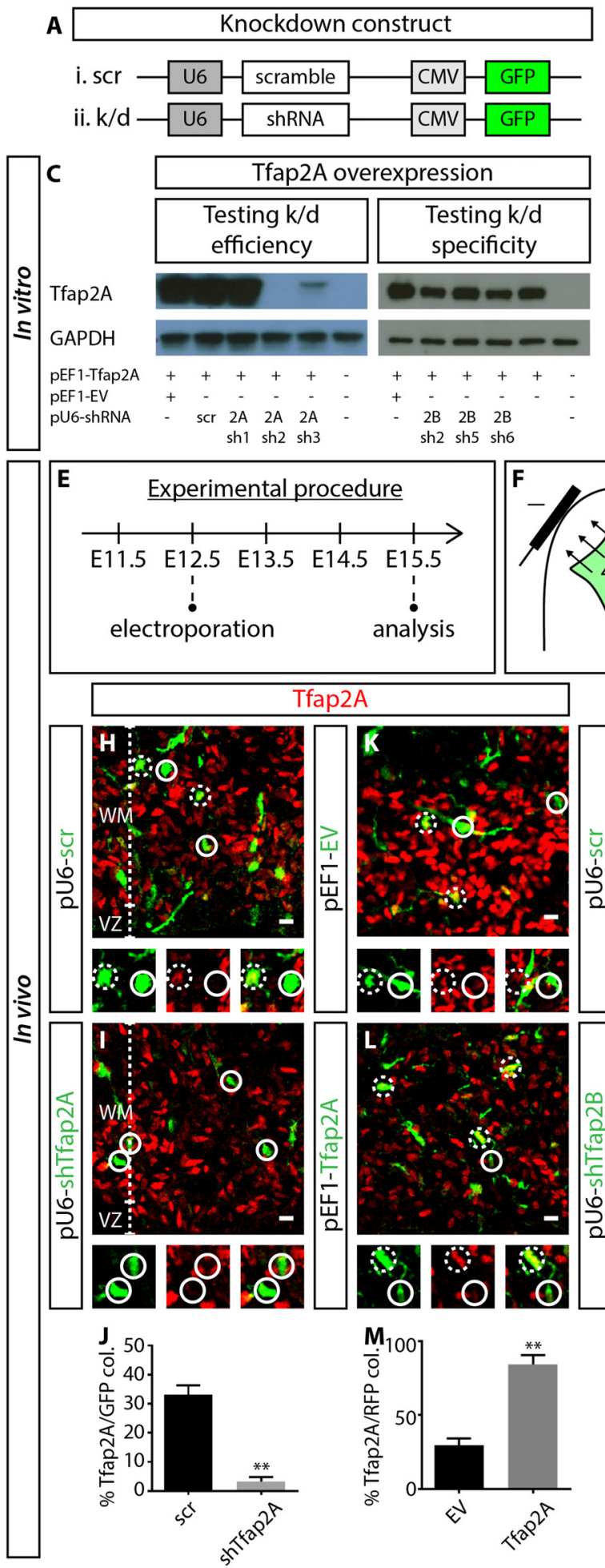
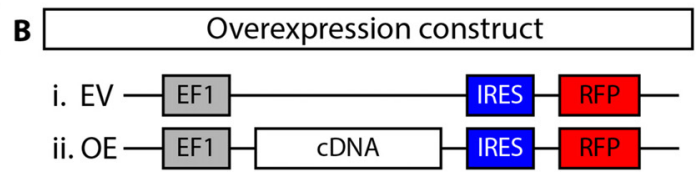

D

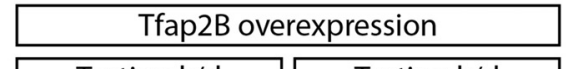

\begin{tabular}{|c|c|}
\hline $\begin{array}{c}\text { Testing } \mathrm{k} / \mathrm{d} \\
\text { efficiency }\end{array}$ & $\begin{array}{l}\text { Testing } \mathrm{k} / \mathrm{d} \\
\text { specificity }\end{array}$ \\
\hline
\end{tabular}

Tfap2B

GAPDH

pEF1-Tfap2B pEF1-EV pU6-shRNA
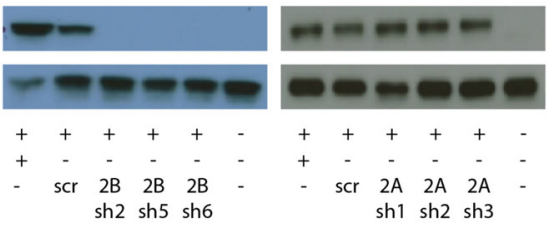

$\operatorname{sh} 1 \operatorname{sh} 2 \operatorname{sh} 3$
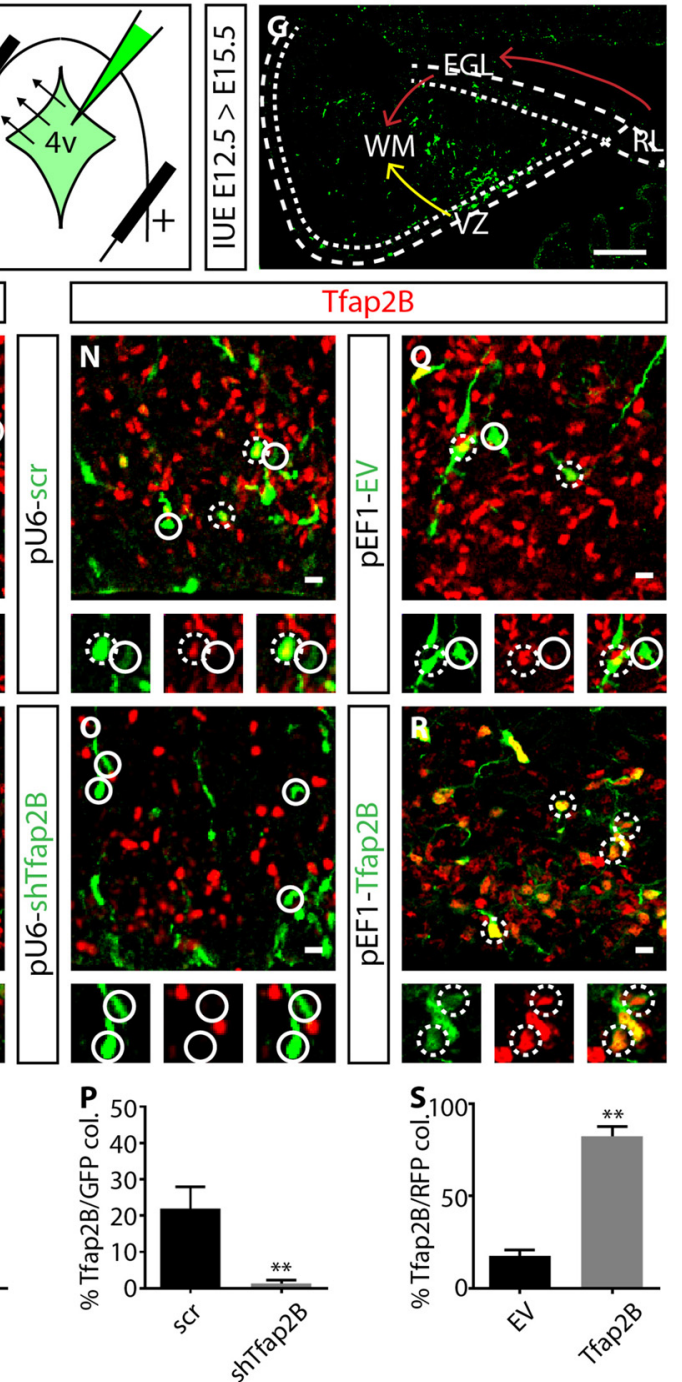

FIGURE 5 | Manipulating the expression of Tfap2A and Tfap2B. (A,B) Plasmid constructs used to manipulate the expression of Tfap2A and Tfap2B. (C,D) Testing OE and knockdown constructs in vitro in human embryonic kidney 293T (HEK-293T) cells. Co-transfection revealed that 2Ash2 and 2Bsh2 are the most efficient (left) and specific (right) in knocking down Tfap2A (C) and Tfap2B (D) expression respectively. (E-G) Strategy for manipulating Tfap2A and Tfap2B expression in utero and experimental timeline. Transfected cells originating from the $\mathrm{VZ}$ migrate into the WM (yellow arrow, $\mathbf{G}$ ) while cells originating from the RL migrate tangentially along the external germinal layer (EGL) before descending into the WM (red arrow, G). (H-M) Tfap2A-knockdown abolishes Tfap2A expression (3 $\pm 2 \%$ vs. $33 \pm 3 \%$ in

(Continued) 


\section{FIGURE 5 | Continued}

controls, $p \leq 0.01$; (H-J) control: $n=3$ mice, 115 cells in 11 sections; $2 \mathrm{~A} \mathrm{k/d:}$ $n=3$ mice, 187 cells in 14 sections) while ectopic expression of Tfap2A results in an increase in Tfap $2 \mathrm{~A}^{+}$cells ( $84 \pm 6 \%$ vs. $30 \pm 4 \%$ in controls, $p \leq 0.01$; (K-M) control: $n=3$ mice, 372 cells in 17 sections; 2A OE: $n=3$ mice, 276 cells in 12 sections). (N-S) Similarly Tfap2B-knockdown abolishes Tfap2B expression ( $1 \pm 1 \%$ vs. $22 \pm 6 \%$ in controls, $p \leq 0.01$; (N-P) control: $n=3$ mice, 121 cells in 11 sections; $2 \mathrm{~B} \mathrm{k} / \mathrm{d}: n=3$ mice, 192 cells in 12 sections) while ectopic expression of Tfap2B results in an increase in Tfap2B $^{+}$cells ( $82 \pm 5 \%$ vs. $18 \pm 3 \%$ in controls, $p \leq 0.01$; (Q-S) control: $n=3$ mice, 276 cells in 12 sections; 2B OE: $n=3$ mice, 366 cells in 13 sections). Continuous circles indicate a lack of colocalization and broken circles indicate colocalization of transfected cells with respective markers. Abbreviations: $4 \mathrm{v}$, 4th ventricle; $\mathrm{EGL}$, external germinal layer; $\mathrm{EV}$, empty vector; $\mathrm{k} / \mathrm{d}$, knockdown; OE, overexpression; RL, rhombic lip; WM, scr, scramble; white matter; VZ, ventricle zone. Values represent the mean $\pm \mathrm{SEM}$, ${ }^{*} p \leq 0.05,{ }^{* *} p \leq 0.01$. Scale bar $=100 \mu \mathrm{m}$ (G), $10 \mu \mathrm{m}(\mathbf{H}, \mathbf{I}, \mathbf{K}, \mathbf{L}, \mathbf{N}, \mathbf{O}, \mathbf{Q}, \mathbf{R})$

interneurons, we found a two-fold increase in the number of $\mathrm{Pax}^{+}$interneurons in Tfap2A-misexpressed cells relative to control in the WM (Figures 6A,B,D). No change was observed in the number of $\mathrm{Pax}^{+} \mathrm{RL}$-derived cells within Tfap2Amisexpressed cells (Figures 6E,F,H). Additionally, misexpression of Tfap2A or Tfap2B had no impact on the expression of CBP (Figures 6I-L). Together we show that the expression of Tfap2A, but not Tfap2B, has the ability to direct specification of $\mathrm{Pax}_{2}{ }^{+}$ GABAergic interneurons. Conversely, the expression of Tfap2B, but not Tfap2A can suppress the expression of Pax6.

To determine the requirements of Tfap 2 for specification of GABAergic neurons, we assessed the effects of knocking down the expression of Tfap2A or Tfap2B on the expression of Pax2, Pax6 and CBP at E15.5. We found a $\sim 15 \%$ reduction in the number of $\mathrm{Pax} 2^{+}$interneurons in Tfap2B-knockdown cells in the WM (Figures 7A,C,D). In contrast, no change in number of Pax2 ${ }^{+}$interneurons were observed in Tfap2A-knockdown cells (Figures 7A,B,D). Knockdown of Tfap2A or Tfap2B had no impact on the expression of Pax6 as predicted (Figures 7E-H). Knockdown of Tfap2B results in a modest reduction in the number of $\mathrm{CBP}^{+}$Purkinje cells, although Purkinje cells do not typically express Tfap2B (Figures 2, 7J-L). No change in number of $\mathrm{CBP}^{+}$cells was detected following Tfap2A knockdown (Figures 7I,K,L). Moreover, because Purkinje cells are scarcely transfected at E12.5 (Figure 7L), our results suggest that Tfap2A and Tfap2B are unable to influence CBP expression. Knockdown of Tfap2B in the VZ of the developing cerebellum at E12.5 results in a decrease of Pax2 expression, indicating that Tfap2B is necessary for the specification of cerebellar GABAergic interneurons. Together, our results demonstrate that Tfap2A and Tfap2B have independent roles in directing the diversification of cerebellar GABAergic neuronal subtypes in the cerebellum. Moreover, our results indicate that only Tfap2B is indispensable for the specification of cerebellar GABAergic interneurons.

\section{DISCUSSION}

GABAergic neurons in the cerebellar cortex are subdivided into projection neurons and interneurons, consisting of at least four subtypes derived from the same pool of multipotent

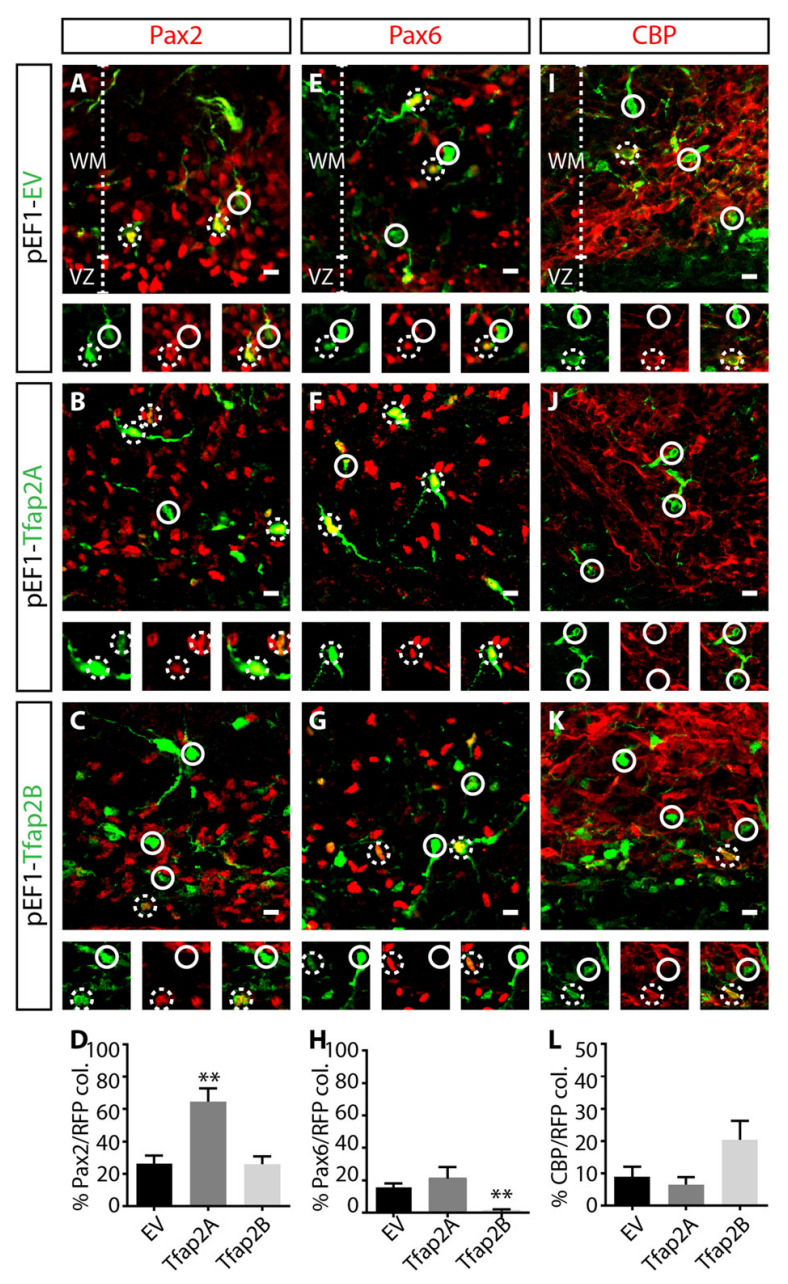

FIGURE 6 | Tfap2A misexpression results in an increase in Pax2 expression, while Tfap2B misexpression results in a decrease in the expression of Pax6. (A-L) Consequences of Tfap2A and Tfap2B misexpression on generation of cerebellar neuronal subpopulations. Misexpression of Tfap2A results in an increase in the number of $\mathrm{Pax} 2^{+}$cells $(54 \pm 11 \%$ vs. $26 \pm 5 \%$ in controls, $p \leq 0.01$; (A,B,D) control: $n=3$ mice, 347 cells in 13 sections; $2 \mathrm{~A}$ OE: $n=3$ mice, 130 cells in 14 sections), but misexpression of Tfap2B did not change the number of $\mathrm{Pax}^{+}$cells compared to controls $(24 \pm 6 \%$ vs. $26 \pm 5 \%$ in controls, $p=0.88$; (B-D) control: $n=3$ mice, 347 cells in 12 sections; 2B OE: $n=3$ mice, 212 cells in 12 sections). Misexpression of Tfap2B, but not Tfap2A, results in a decrease in the number of $\mathrm{Pax}^{+}$cells (Tfap2B: $1 \pm 1 \%$ vs. $16 \pm 3 \%$ in controls, $p \leq 0.01$; (F-H) Tfap2A: $19 \pm 8 \%$ vs. $16 \pm 3 \%$ in controls, $p=0.66$; $(\mathbf{E}, \mathbf{G}, \mathbf{H})$ control: $n=3$ mice, 542 cells in 14 sections; 2A OE: $n=3$ mice, 65 cells in 8 sections; 2B OE: $n=3$ mice, 337 cells in 13 sections). Misexpression of Tfap2A and Tfap2B has no impact on the number of $\mathrm{CBP}^{+}$Purkinje cells (Tfap2A: $6 \pm 2 \%$ vs. $9 \pm 3 \%$ in controls, $p=0.85$; (I,K,L) Tfap2B: $20 \pm 6 \%$ vs. $9 \pm 3 \%$ in controls, $p=0.063$ (J-L) control: $n=3$ mice, 365 cells in 15 sections; 2 A OE: $n=3$ mice 160 cells in 10 sections; 2B OE: $n=261$ cells in 9 sections). Continuous circles indicate lack of colocalization and broken circles indicate colocalization of transfected cells with respective markers. Abbreviations: VZ, ventricular zone; WM, white matter. Values represent the mean $\pm \mathrm{SEM},{ }^{*} p \leq 0.05$, ${ }^{* *} p \leq 0.01$. Scale bar $=10 \mu \mathrm{m}$.

progenitors (Hoshino et al., 2005; Pascual et al., 2007; Yamada et al., 2014), but the transcriptional program that directs this diversification is not well defined. To explore determinants of the 


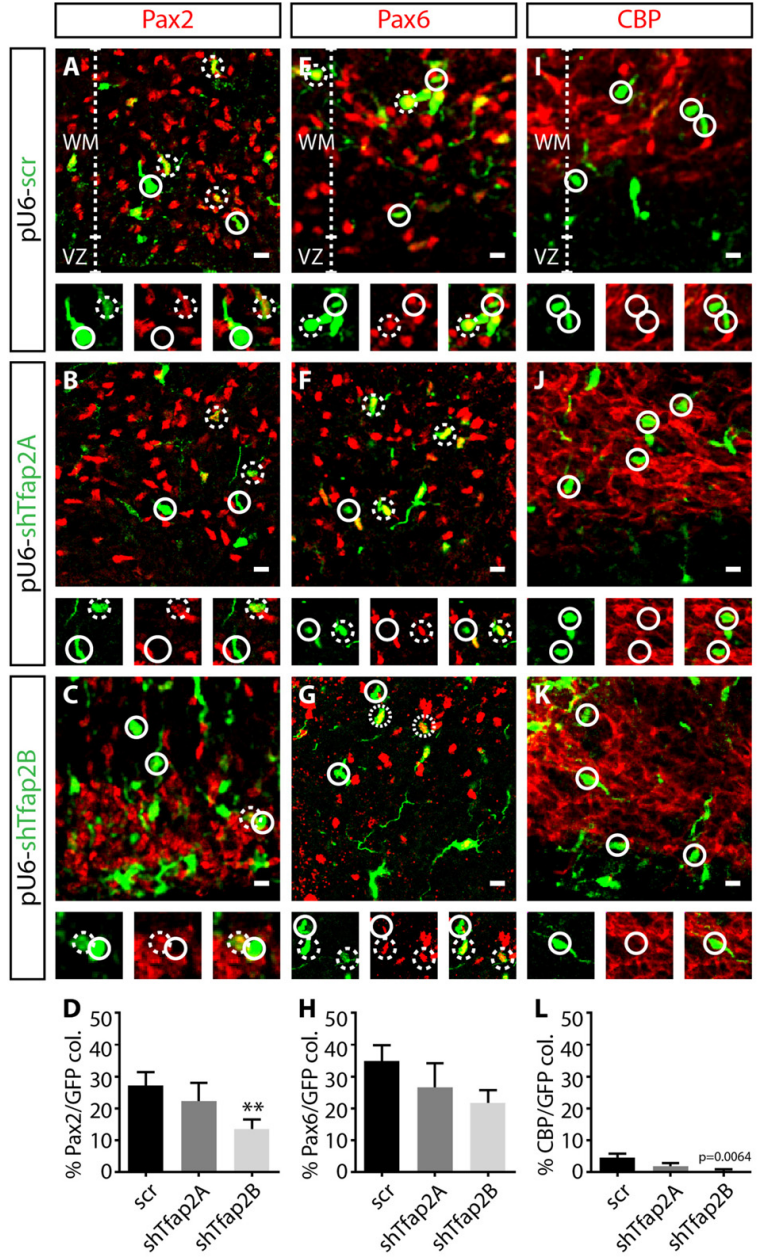

FIGURE 7 | Knockdown of the expression of Tfap2B, but not Tfap2A, results in a reduction in Pax2 expression. (A-H) Knockdown of Tfap2A expression in the VZ does not affect the number of Pax ${ }^{+}$cells $(22 \pm 6 \%$ vs. $27 \pm 4 \%$ in controls, $p=0.53$; (A,B,D) control: $n=3$ mice, 153 cells in 12 sections; $2 \mathrm{~A}$ $\mathrm{k} / \mathrm{d}: n=3$ mice, 87 cells in 14 sections) or number of $\mathrm{Pax}^{+}$cells compared to controls ( $27 \pm 8 \%$ vs. $34 \pm 4 \%$ in controls, $p=0.29$; $(\mathbf{E}, \mathbf{F}, \mathbf{H})$ control: $n=3$ mice, 241 cells in 13 sections; $2 \mathrm{~A} \mathrm{k} / \mathrm{d}: n=3$ mice, 188 cells in 13 sections). However, knockdown of Tfap2B expression results in a significant decrease in number of $\mathrm{Pax}^{+}$cells (13 $\pm 3 \%$ vs. $27 \pm 4 \%$ in controls, $p \leq 0.01$; (A,C,D) control: $n=3$ mice, 153 cells in 12 sections; $2 \mathrm{~B}$ $\mathrm{k} / \mathrm{d}: n=3$ mice, 391 cells in 26 sections), without affecting the number of Pax6 $^{+}$cells $(22 \pm 4 \%$ vs. $34 \pm 4 \%$ in controls, $p=0.054$; (E,G,H) control: $n=3$ mice, 241 cells in 13 sections; $2 \mathrm{~B} \mathrm{k} / \mathrm{d}: n=3$ mice, 211 cells in 12 sections). (I-L) A scant percentage of $\mathrm{CBP}^{+}$Purkinje cells are transfected, although knockdown of Tfap2B, but not Tfap2A, slightly decreased this subpopulation (Tfap2B: $0.5 \pm 0.5 \%$ vs. $4 \pm 1 \%$ in controls, $p=0.0064$; (J-L) Tfap2A: $2 \pm 1 \%$ vs. $4 \pm 1 \%$ in controls, $p=0.067$; (I,J,L) control: $n=3$ mice, 307 cells in 13 sections; $2 \mathrm{~A} \mathrm{k} / \mathrm{d}: n=3$ mice, 206 cells in 14 sections; $2 \mathrm{~B} \mathrm{k} / \mathrm{d}$ : $n=3$ mice, 253 cells in 13 sections). Continuous circles indicate lack of colocalization and broken circles indicate colocalization of transfected cells with respective markers. Abbreviations: VZ, ventricular zone; WM, white matter. Values represent the mean \pm SEM, ${ }^{*} p \leq 0.05,{ }^{* *} p \leq 0.01$. Scale bar $=10 \mu \mathrm{m}$.

specification of GABAergic neuron progenitors into GABAergic neuronal subtypes, we examined the expression and function of Tfap2 family of transcription factors (summarized in Figure 8).
We discuss how the differential expression of Tfap2A and Tfap2B defines GABAergic neuronal subtypes and their contribution to the generation and specification of cerebellar GABAergic neurons.

\section{Combinatorial Expression of}

Tfap2 Transcription Factors and Cerebellar GABAergic Neuronal Subtypes

There is emerging evidence that GABAergic neuronal subtypes are defined by their unique expression of transcription factors (Helms and Johnson, 2003; Wonders and Anderson, 2006; Hoshino, 2012; Achim et al., 2014). In the cortex, for instance, GABAergic interneurons are derived from Nkx2.1 domain of the medial ganglionic eminence and ventral caudal ganglionic eminence (Cobos et al., 2006; Wonders and Anderson, 2006). Subsequently, GABAergic neuronal subtypes can be differentiated by their distinct combinatorial expression of Dlx1/2, Dlx5/6 and Lhx6 (Cobos et al., 2006; Wonders and Anderson, 2006). In more caudal regions of the nervous system, the differential expression of Lbx1, Lhx1/5, Pax2, Gsh1/2, Dbx2 and GATA2/3 defines GABAergic interneuron subtypes in the spinal cord; $\operatorname{Lhx} 1 / 5$ is expressed by all GABAergic neurons and Pax2 is expressed only by interneurons in the cerebellum (Helms and Johnson, 2003; Hori and Hoshino, 2012). Additionally, Ptfla is expressed by all early GABAergic precursors in both the cerebellum and spinal cord (Hori and Hoshino, 2012). Thus, in comparison to the cortex and spinal cord, there are less distinguishing molecular features for labeling and monitoring of GABAergic neuronal subtypes in the cerebellum.

We show in this study that the combinatorial expression of Tfap2A and Tfap2B may distinguish GABAergic projection neurons from interneurons in the developing cerebellum. In the adult cerebellum, Tfap2A is expressed in all GABAergic neurons, whereas Tfap2B is selectively expressed in the interneuronal population (Figure 2). In contrast to Ptfla and Olig2, whose expression is extinguished by E13.5 (Pascual et al., 2007; Seto et al., 2014a; Ju et al., 2016), the expression of Tfap2 transcription factors persists into adulthood. However, Tfap2B might be transiently expressed in early Purkinje cells during embryonic development (Figure 3). Our discovery that Tfap2 transcription factors are dynamically and, perhaps, differentially expressed by GABAergic neuronal subtypes in the cerebellum, provides a novel set of molecular markers that can complement a growing list of genetic tools for future characterization and lineage analysis of these neurons. There is now a number of mouse lines for the tagging and monitoring of cerebellar GABAergic neurons: Gad67::GFP and Ptf1a::Cre label all GABAergic neurons (Yamanaka et al., 2004; Pascual et al., 2007; Yamada et al., 2014), Corl2::GFP and Olig2::Cre mark projection neurons (Nakatani et al., 2014; Seto et al., 2014b; Ju et al., 2016) and Pax2::GFP selectively labels GABAergic interneurons (Leto et al., 2006; Weisheit et al., 2006). The emergence of these tools will permit a systematic examination of the development, function as well as molecular profile of cerebellar GABAergic neuronal subtypes. 


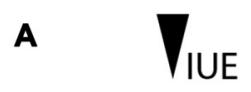

E12.5

E13.5

harvest

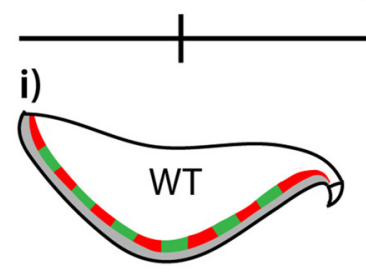

ii)
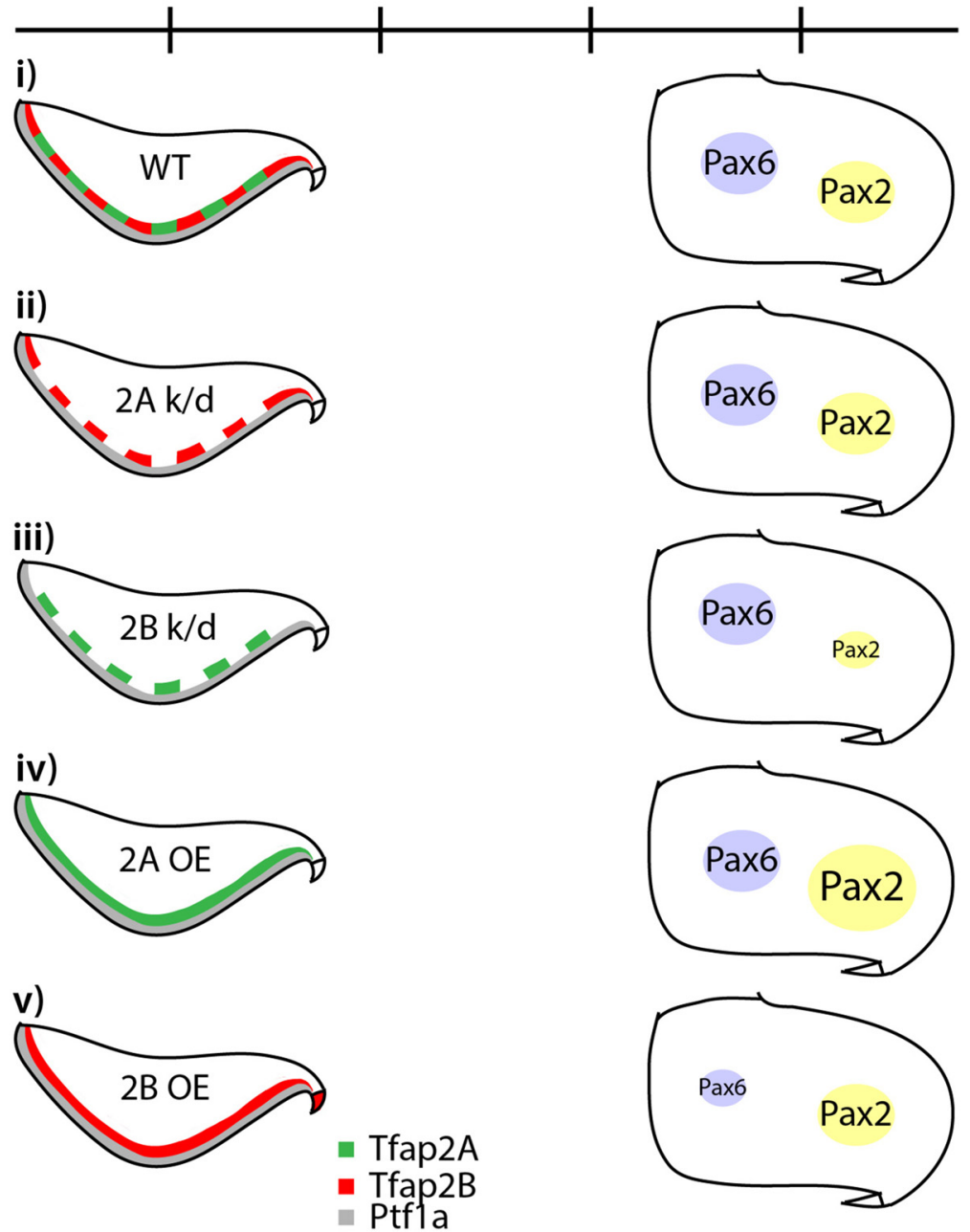

B

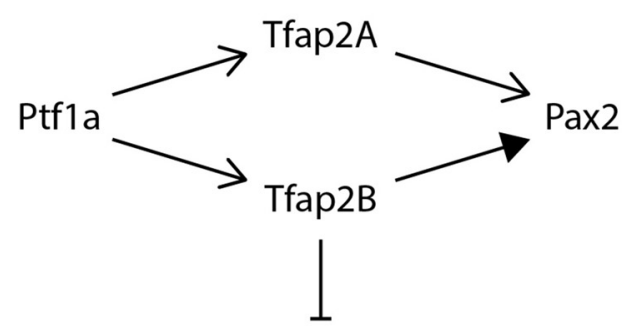

Pax6

FIGURE 8 | Summary of the activities of Tfap2A and Tfap2B in GABAergic interneuron specification. (A) Summary of results from knocking down and ectopic expression of Tfap2A and Tfap2B. (Ai) In a wild-type, expression of Tfap2A and Tfap2B occur in an overlapping manner in the ventricular zone at E12.5 which is observed superior to Ptf1a territory. Some expression of Pax6 and Pax2 is observed in the white matter of the developing cerebellum at E15.5. Knockdown of Tfap2A does not show any changes in the expression of Pax2 or Pax6 (Aii). Knockdown of Tfap2B results in a decrease in Pax2 expression (Aiii). Ectopic expression of Tfap2A results in an increase in Pax2 expression (Aiv), while ectopic expression of Tfap2B results in a decrease in Pax6 expression (Av). (B) Proposed activities of Tfap2A and Tfap2B in the development of cerebellar neurons. Expression of Tfap2A and Tfap2B downstream of Ptf1a play distinct roles to ensure generation of $\mathrm{Pax} 2^{+}$interneurons. Tfap2A may also function to produce Purkinje cells, but at earlier developmental stages. In addition to generation of GABAergic interneurons, Tfap2B plays a role in the suppression of Pax6 expression. Abbreviations: IUE, in utero electroporation; $\mathrm{k} / \mathrm{d}$, knockdown; OE, overexpression; RL, rhombic lip; VZ, ventricular zone; WT, wild-type. 


\section{Distinct Roles of Tfap2A and Tfap2B in Establishment of GABAergic Neuronal Subtype Identity}

Tfap2 family of transcription factors regulates a myriad of developmental processes in the nervous system, kidney, skeleton, limbs, skin and eye (Schorle et al., 1996; Zhang et al., 1996; Moser et al., 1997; Nottoli et al., 1998; West-Mays et al., 1999; Eckert et al., 2005; Seberg et al., 2017). Members of this family exhibit functional redundancy in zebrafish. For instance, Tfap2A and Tfap2E are redundant in their regulation of melanophore development (Van Otterloo et al., 2010). Additionally, Tfap2A and Tfap $2 \mathrm{C}$ are redundant in their induction of neural crest development (Hoffman et al., 2007; Li and Cornell, 2007). In the mouse, however, members of this family appear to play more discrete roles in developmental processes. For example, Tfap2A is indispensable for craniofacial, eye, and limb development (Schorle et al., 1996; Nottoli et al., 1998); and, Tfap2B is indispensable for kidney development (Moser et al., 1997). Consistently, our results indicate that Tfap2A and Tfap2B play independent roles in the specification of GABAergic interneurons during mouse cerebellar development.

There is growing evidence that, in addition to Ptfla, Tfap2A and Tfap2B play a crucial role in the specification of GABAergic neuronal subtypes (Figures 6, 7). The expression of Ptfla in neural precursors directs generation of GABAergic neurons and suppresses generation of glutamatergic neurons in the cerebellum, spinal cord and retina (Glasgow et al., 2005; Hoshino et al., 2005; Nakhai et al., 2007; Pascual et al., 2007). Tfap $2 \mathrm{~A}$ and Tfap2B expression is dependent on Ptfla in the retina (Jin et al., 2015). Both transcription factors have the ability to promote generation of GABAergic/glycinergic amacrine cells and concomitantly suppress the generation of excitatory photoreceptors and bipolar cells (Jin et al., 2015). In this study, we show that following determination of GABAergic fate of neural precursors in the VZ by Ptfla, Tfap2A and Tfap2B subsequently serve to ensure generation of GABAergic neurons and suppression of excitatory neurons. Tfap2A alone has the ability to promote generation of GABAergic interneurons while Tfap2B, but not Tfap2A, can suppress the generation of excitatory cells. Thus, Tfap2A and Tfap2B appear to have distinct roles in the specification of GABAergic/glycinergic neurons in the cerebellum, and may serve to delegate the activities of Ptfla similar to the function of Tfap2A/B in the retina (Figure $8 B$ ).

Distinguishing molecular features of GABAergic interneurons vs. GABAergic projection neurons in the cerebellum have not be well defined. A set of bHLH transcription factors Ascl1 and Ngn1 may be involved in specification of interneurons and projection neurons, respectively. Ascl1 is required for generation of $\mathrm{Pax} 2^{+}$interneurons, but not Purkinje cells, whereas Ngn1 is required for generation of Purkinje cells, but not $\mathrm{Pax}_{2}{ }^{+}$interneurons (Grimaldi et al., 2009; Lundell et al., 2009). Lim homeodomain transcription factors Lhx1 and Lhx5 and their cofactor Ldb1 are required for production of Purkinje cells, but not $\mathrm{Pax}^{+}$interneurons (Zordan et al., 2008). Additionally, the transcription factor Corl2 plays a role in maturation of Purkinje cells (Wang et al., 2011). Besides Ascl1, cerebellar GABAergic interneurons are dependent on cyclin D2 and cell-cycle dynamics (Huard et al., 1999; Leto et al., 2011). In this study, we add to this list members of Tfap 2 family of transcription factors whose expression defines cerebellar GABAergic projection vs. interneurons, and acts to ensure specification of GABAergic interneurons, but not projection neurons.

\section{AUTHOR CONTRIBUTIONS}

$\mathrm{NZ}$ and AIC designed the studies and prepared the manuscript with comments from all authors. NZ performed all the experiments and analyzed the data. SPK carried out in utero electroporation experiments and revised the manuscript. ART carried out analysis in the DCN.

\section{ACKNOWLEDGMENTS}

We are grateful to Thomas Jessell and Susan Brenner-Morton for Tfap2B antibody, and Chris Wright for Ptfla antibody. We thank Guo Lanboling for advice on in utero electroporation. We thank J. Nicholas Betley, Toh Hean Ch'ng and Mark Featherstone for comments on the manuscript.

\section{SUPPLEMENTARY MATERIAL}

The Supplementary Material for this article can be found online at: http://journal.frontiersin.org/article/10.3389/fnmol. 2017.00281/full\#supplementary-material

FIGURE S1 | Tfap2A is selectively expressed in the Purkinje cell layer during development but is uniformly expressed in the adult cerebellum. (A-D) Colocalization of Tfap2A (red, $\mathbf{B}^{\prime}, \mathbf{C}^{\prime}, \mathbf{D}^{\prime}, \mathbf{B}^{\prime \prime \prime}, \mathbf{C}^{\prime \prime \prime}, \mathbf{D}^{\prime \prime \prime}$ ) and CBP (green, $\left.\mathbf{B}^{\prime \prime}, \mathbf{C}^{\prime \prime}, \mathbf{D}^{\prime \prime}, \mathbf{B}^{\prime \prime \prime}, \mathbf{C}^{\prime \prime \prime}, \mathbf{D}^{\prime \prime \prime}\right)$ at early post-natal day 7 show selective Purkinje cell expression in the developing cerebellum. (E-H) The expression of Tfap2A (red, $\mathbf{F}^{\prime}, \mathbf{G}^{\prime}, \mathbf{H}^{\prime}, \mathbf{F}^{\prime \prime \prime}, \mathbf{G}^{\prime \prime \prime}, \mathbf{H}^{\prime \prime \prime}$ ) and PVA (green, $\mathbf{F}^{\prime \prime}, \mathbf{G}^{\prime \prime}, \mathbf{H}^{\prime \prime}, \mathbf{F}^{\prime \prime \prime}, \mathbf{G}^{\prime \prime \prime}, \mathbf{H}^{\prime \prime \prime}$ ) in Purkinje cells from different regions of the cerebellum does not show a medio-lateral distribution pattern. Analysis was performed on coronal sections of the cerebellum from P60 mice. Broken circles indicate cells with colocalized expression, continuous circles indicate no colocalization. Abbreviations: CBP, calbindin; DCN, deep cerebellar nuclei; IGL, internal granular layer ML, molecular layer; PCL, Purkinje cell layer; PVA, parvalbumin. Scale bar = $1000 \mu \mathrm{m}(\mathbf{A}, \mathbf{E}), 20 \mu \mathrm{m}\left(\mathbf{B}^{\prime}-\mathbf{D}^{\prime \prime \prime}, \mathbf{F}^{\prime}-\mathbf{H}^{\prime \prime \prime}\right)$.

FIGURE S2 | Tfap2A, but not Tfap2B, is expressed in GABAergic neurons in the DCN. (A-F) Expression of Tfap2A (green, $\mathbf{A}-\mathbf{C}$ ) is restricted to small GABAergic neurons of the DCN, marked by MAP2 (red) and Gad67 (blue). Tfap2B expression, on the other hand, is absent in all three nuclei in the DCN. Scale bar $=10 \mu \mathrm{m}$.

FIGURE S3 | Tfap2A and Tfap2B are expressed by GABAergic interneuron precursors in the embryonic cerebellum. (A-C) Delineation of the E12.5 cerebellum with Ptf1a (red, A), a molecular marker that labels the ventricular zone, and Pax2 (green, B), a GABAergic interneuron precursor marker. (D-I) A subset of Tfap2A (D) and Tfap2B (G) colocalizes with Pax2 interneuron marker in the embryonic cerebellum. Abbreviations: VZ, ventricular zone; WM, white matter. Scale bar $=10 \mu \mathrm{m}$. 
FIGURE S4 | In utero electroporation of the cerebellum at E12.5 transfects cells of the ventricular zone and rhombic lip. (A,B) Summary of targeted regions and strategy for in utero electroporation. (C-I) Schematic diagram of the expression of respective molecular markers in the embryonic cerebellum at E13.5. ( $\left.\mathbf{C}^{\prime}-\mathbf{E}^{\prime \prime}\right)$ GABAergic molecular markers, Ptf1a and Olig2, label the ventricular zone while Pax2 labels the white matter layer.

\section{REFERENCES}

Achim, K., Salminen, M., and Partanen, J. (2014). Mechanisms regulating GABAergic neuron development. Cell. Mol. Life Sci. 71, 1395-1415. doi: 10.1007/s00018-013-1501-3

Andersen, B. B., Korbo, L., and Pakkenberg, B. (1992). A quantitative study of the human cerebellum with unbiased stereological techniques. J. Comp. Neurol. 326, 549-560. doi: 10.1002/cne.903260405

Borromeo, M. D., Meredith, D. M., Castro, D. S., Chang, J. C., Tung, K. C., Guillemot, F., et al. (2014). A transcription factor network specifying inhibitory versus excitatory neurons in the dorsal spinal cord. Development 141, 2803-2812. doi: 10.1242/dev.105866

Chizhikov, V. V., Lindgren, A. G., Currle, D. S., Rose, M. F., Monuki, E. S., and Millen, K. J. (2006). The roof plate regulates cerebellar cell-type specification and proliferation. Development 133, 2793-2804. doi: 10.1242/dev.02441

Cobos, I., Long, J. E., Thwin, M. T., and Rubenstein, J. L. (2006). Cellular patterns of transcription factor expression in developing cortical interneurons. Cereb. Cortex 16, i82-i88. doi: 10.1093/cercor/bhk003

D’Angelo, E., Solinas, S., Mapelli, J., Gandolfi, D., Mapelli, L., and Prestori, F. (2013). The cerebellar Golgi cell and spatiotemporal organization of granular layer activity. Front. Neural Circuits 7:93. doi: 10.3389/fncir.2013. 00093

De Zeeuw, C. I., Hansel, C., Bian, F., Koekkoek, S. K., van Alphen, A. M., Linden, D. J., et al. (1998). Expression of a protein kinase C inhibitor in Purkinje cells blocks cerebellar LTD and adaptation of the vestibulo-ocular reflex. Neuron 20, 495-508. doi: 10.1016/s0896-6273(00)80990-3

Eccles, J. C., Ito, M., and Szentágothai, J. (1967). The Cerebellum as a Neuronal Machine. Berlin, New York, NY: Springer-Verlag.

Eckert, D., Buhl, S., Weber, S., Jäger, R., and Schorle, H. (2005). The AP-2 family of transcription factors. Genome Biol. 6:246. doi: 10.1186/gb-2005-6-13-246

Glasgow, S. M., Henke, R. M., Macdonald, R. J., Wright, C. V., and Johnson, J. E. (2005). Ptfla determines GABAergic over glutamatergic neuronal cell fate in the spinal cord dorsal horn. Development 132, 5461-5469. doi: 10.1242/dev. 02167

Grimaldi, P., Parras, C., Guillemot, F., Rossi, F., and Wassef, M. (2009). Origins and control of the differentiation of inhibitory interneurons and glia in the cerebellum. Dev. Biol. 328, 422-433. doi: 10.1016/j.ydbio.2009.02.008

Heiney, S. A., Kim, J., Augustine, G. J., and Medina, J. F. (2014). Precise control of movement kinematics by optogenetic inhibition of Purkinje cell activity. J. Neurosci. 34, 2321-2330. doi: 10.1523/jneurosci.4547-13.2014

Helms, A. W., and Johnson, J. E. (2003). Specification of dorsal spinal cord interneurons. Curr. Opin. Neurobiol. 13, 42-49. doi: 10.1016/s09594388(03)00010-2

Hoffman, T. L., Javier, A. L., Campeau, S. A., Knight, R. D., and Schilling, T. F. (2007). Tfap2 transcription factors in zebrafish neural crest development and ectodermal evolution. J. Exp. Zool. B Mol. Dev. Evol. 308, 679-691. doi: 10.1002/jez.b.21189

Hori, K., and Hoshino, M. (2012). GABAergic neuron specification in the spinal cord, the cerebellum and the cochlear nucleus. Neural Plast. 2012:921732. doi: $10.1155 / 2012 / 921732$

Hoshino, M. (2012). Neuronal subtype specification in the cerebellum and dorsal hindbrain. Dev. Growth Differ. 54, 317-326. doi: 10.1111/j.1440-169x.2012. 01330.x

Hoshino, M., Nakamura, S., Mori, K., Kawauchi, T., Terao, M., Nishimura, Y. V., et al. (2005). Ptfla, a bHLH transcriptional gene, defines GABAergic neuronal fates in cerebellum. Neuron 47, 201-213. doi: 10.1016/j.neuron.2005. 06.007

Huard, J. M., Forster, C. C., Carter, M. L., Sicinski, P., and Ross, M. E. (1999). Cerebellar histogenesis is disturbed in mice lacking cyclin D2. Development 126, 1927-1935.
(F'-G') Glutamatergic molecular markers, Pax6 and calretinin, label transfected cells that arise from the rhombic lip. $\left(\mathbf{H}^{\prime}-\mathbf{I}^{\prime \prime}\right)$ Tfap2A and Tfap2B cells are mostly found in the white matter layer which are preferentially targeted during in utero electroporation. Abbreviations: NTZ, nuclear transitory zone; RL, rhombic lip; WM, white matter; VZ, ventricular zone. Scale bar $=10 \mu \mathrm{m}$.

Ino, H. (2004). Immunohistochemical characterization of the orphan nuclear receptor $\operatorname{ROR} \alpha$ in the mouse nervous system. J. Histochem. Cytochem. 52, 311-323. doi: 10.1177/002215540405200302

Ito, M. (2006). Cerebellar circuitry as a neuronal machine. Prog. Neurobiol. 78, 272-303. doi: 10.1016/j.pneurobio.2006.02.006

Jin, K., Jiang, H., Xiao, D., Zou, M., Zhu, J., and Xiang, M. (2015). Tfap $2 \mathrm{a}$ and $2 \mathrm{~b}$ act downstream of Ptfla to promote amacrine cell differentiation during retinogenesis. Mol. Brain 8:28. doi: 10.1186/s13041-0150118-x

Ju, J., Liu, Q., Zhang, Y., Liu, Y., Jiang, M., Zhang, L., et al. (2016). Olig2 regulates Purkinje cell generation in the early developing mouse cerebellum. Sci. Rep. 6:30711. doi: 10.1038/srep30711

Korbo, L., Andersen, B. B., Ladefoged, O., and Møller, A. (1993). Total numbers of various cell types in rat cerebellar cortex estimated using an unbiased stereological method. Brain Res. 609, 262-268. doi: 10.1016/00068993(93)90881-m

Leto, K., Bartolini, A., Di Gregorio, A., Imperiale, D., De Luca, A., Parmigiani, E., et al. (2011). Modulation of cell-cycle dynamics is required to regulate the number of cerebellar GABAergic interneurons and their rhythm of maturation. Development 138, 3463-3472. doi: 10.1242/dev.064378

Leto, K., Bartolini, A., Yanagawa, Y., Obata, K., Magrassi, L., Schilling, K., et al. (2009). Laminar fate and phenotype specification of cerebellar GABAergic interneurons. J. Neurosci. 29, 7079-7091. doi: 10.1523/jneurosci.095709.2009

Leto, K., Carletti, B., Williams, I. M., Magrassi, L., and Rossi, F. (2006). Different types of cerebellar GABAergic interneurons originate from a common pool of multipotent progenitor cells. J. Neurosci. 26, 11682-11694. doi: 10.1523/jneurosci.3656-06.2006

Leto, K., and Rossi, F. (2012). Specification and differentiation of cerebellar GABAergic neurons. Cerebellum 11, 434-435. doi: 10.1007/s12311-0110324-8

Li, W., and Cornell, R. A. (2007). Redundant activities of Tfap2a and Tfap $2 \mathrm{c}$ are required for neural crest induction and development of other non-neural ectoderm derivatives in zebrafish embryos. Dev. Biol. 304, 338-354. doi: 10.1016/j.ydbio.2006.12.042

Lundell, T. G., Zhou, Q., and Doughty, M. L. (2009). Neurogenin1 expression in cell lineages of the cerebellar cortex in embryonic and postnatal mice. Dev. Dyn. 238, 3310-3325. doi: 10.1002/dvdy.22165

Machold, R., and Fishell, G. (2005). Math1 is expressed in temporally discrete pools of cerebellar rhombic-lip neural progenitors. Neuron 48, 17-24. doi: 10.1016/j.neuron.2005.08.028

Maricich, S. M., and Herrup, K. (1999). Pax-2 expression defines a subset of GABAergic interneurons and their precursors in the developing murine cerebellum. J. Neurobiol. 41, 281-294. doi: 10.1002/(sici)10974695(19991105)41:2<281::aid-neu10>3.0.c0;2-5

Meredith, D. M., Borromeo, M. D., Deering, T. G., Casey, B. H., Savage, T. K., Mayer, P. R., et al. (2013). Program specificity for Ptfla in pancreas versus neural tube development correlates with distinct collaborating cofactors and chromatin accessibility. Mol. Cell. Biol. 33, 3166-3179. doi: 10.1128/MCB. 00364-13

Miale, I. L., and Sidman, R. L. (1961). An autoradiographic analysis of histogenesis in the mouse cerebellum. Exp. Neurol. 4, 277-296. doi: 10.1016/00144886(61)90055-3

Minaki, Y., Nakatani, T., Mizuhara, E., Inoue, T., and Ono, Y. (2008). Identification of a novel transcriptional corepressor, Corl2, as a cerebellar Purkinje cell-selective marker. Gene Exp. Patterns 8, 418-423. doi: 10.1016/j. gep.2008.04.004

Morales, D., and Hatten, M. E. (2006). Molecular markers of neuronal progenitors in the embryonic cerebellar anlage. J. Neurosci. 26, 12226-12236. doi: 10.1523/JNEUROSCI.3493-06.2006 
Moser, M., Imhof, A., Pscherer, A., Bauer, R., Amselgruber, W., Sinowatz, F., et al. (1995). Cloning and characterization of a second AP-2 transcription factor: AP-2 $\beta$. Development 121, 2779-2788.

Moser, M., Pscherer, A., Roth, C., Becker, J., Mücher, G., Zerres, K., et al. (1997). Enhanced apoptotic cell death of renal epithelial cells in mice lacking transcription factor AP-2 $\beta$. Genes Dev. 11, 1938-1948. doi: 10.1101/gad.11. 15.1938

Nakagawa, S., Watanabe, M., and Inoue, Y. (1997). Prominent expression of nuclear hormone receptor ROR $\alpha$ in Purkinje cells from early development. Neurosci. Res. 28, 177-184. doi: 10.1016/s0168-0102(97)00042-4

Nakatani, T., Minaki, Y., Kumai, M., Nitta, C., and Ono, Y. (2014). The c-Ski family member and transcriptional regulator Corl2/Skor2 promotes early differentiation of cerebellar Purkinje cells. Dev. Biol. 388, 68-80. doi: 10.1016/j. ydbio.2014.01.016

Nakhai, H., Sel, S., Favor, J., Mendoza-Torres, L., Paulsen, F., Duncker, G. I., et al. (2007). Ptfla is essential for the differentiation of GABAergic and glycinergic amacrine cells and horizontal cells in the mouse retina. Development 134, 1151-1160. doi: 10.1242/dev.02781

Nottoli, T., Hagopian-Donaldson, S., Zhang, J., Perkins, A., and Williams, T. (1998). AP-2-null cells disrupt morphogenesis of the eye, face, and limbs in chimeric mice. Proc. Natl. Acad. Sci. U S A 95, 13714-13719. doi: 10.1073/pnas. 95.23.13714

Palay, S. L., and Chan-Palay, V. (1974). Cerebellar Cortex: Cytology and Organization. Berlin, Heidelberg, New York, NY: Springer.

Pascual, M., Abasolo, I., Mingorance-Le Meur, A., Martínez, A., Del Rio, J. A., Wright, C. V., et al. (2007). Cerebellar GABAergic progenitors adopt an external granule cell-like phenotype in the absence of Ptf1a transcription factor expression. Proc. Natl. Acad. Sci. U S A 104, 5193-5198. doi: 10.1073/pnas. 0605699104

Russ, J. B., Borromeo, M. D., Kollipara, R. K., Bommareddy, P. K., Johnson, J. E., and Kaltschmidt, J. A. (2015). Misexpression of ptfla in cortical pyramidal cells in vivo promotes an inhibitory peptidergic identity. J. Neurosci. 35, 6028-6037. doi: 10.1523/JNEUROSCI.3821-14.2015

Schmidt, M., Huber, L., Majdazari, A., Schütz, G., Williams, T., and Rohrer, H. (2011). The transcription factors AP- $2 \beta$ and AP- $2 \alpha$ are required for survival of sympathetic progenitors and differentiated sympathetic neurons. Dev. Biol. 355, 89-100. doi: 10.1016/j.ydbio.2011.04.011

Schorle, H., Meier, P., Buchert, M., Jaenisch, R., and Mitchell, P. J. (1996). Transcription factor AP-2 essential for cranial closure and craniofacial development. Nature 381, 235-238. doi: 10.1038/381235a0

Seberg, H. E., Van Otterloo, E., Loftus, S. K., Liu, H., Bonde, G., Sompallae, R., et al. (2017). TFAP2 paralogs regulate melanocyte differentiation in parallel with MITF. PLoS Genet. 13:e1006636. doi: 10.1371/journal.pgen.1006636

Seto, Y., Ishiwata, S., and Hoshino, M. (2014a). Characterization of Olig2 expression during cerebellar development. Gene Exp. Patterns 15, 1-7. doi: 10.1016/j.gep.2014.02.001

Seto, Y., Nakatani, T., Masuyama, N., Taya, S., Kumai, M., Minaki, Y., et al. (2014b). Temporal identity transition from Purkinje cell progenitors to GABAergic interneuron progenitors in the cerebellum. Nat. Commun. 5:3337. doi: $10.1038 /$ ncomms 4337

Shimada, M., Konishi, Y., Ohkawa, N., Ohtaka-Maruyama, C., Hanaoka, F., Makino, Y., et al. (1999). Distribution of AP-2 subtypes in the adult mouse brain. Neurosci. Res. 33, 275-280. doi: 10.1016/s0168-0102(99)00017-6

Sillitoe, R. V., and Joyner, A. L. (2007). Morphology, molecular codes, and circuitry produce the three-dimensional complexity of the cerebellum. Annu. Rev. Cell Dev. Biol. 23, 549-577. doi: 10.1146/annurev.cellbio.23.090506.123237

Thach, W. T., and Bastian, A. J. (2004). Role of the cerebellum in the control and adaptation of gait in health and disease. Prog. Brain Res. 143, 353-366. doi: 10.1016/s0079-6123(03)43034-3

Van Otterloo, E., Li, W., Bonde, G., Day, K. M., Hsu, M. Y., and Cornell, R. A. (2010). Differentiation of zebrafish melanophores depends on transcription factors AP2alpha and AP2 epsilon. PLoS Genet. 6:e1001122. doi: 10.1371/journal.pgen.1001122

Wang, B., Harrison, W., Overbeek, P. A., and Zheng, H. (2011). Transposon mutagenesis with coat color genotyping identifies an essential role for Skor2 in sonic hedgehog signaling and cerebellum development. Development 138, 4487-4497. doi: 10.1242/dev.067264

Wang, V. Y., Rose, M. F., and Zoghbi, H. Y. (2005). Math1 expression redefines the rhombic lip derivatives and reveals novel lineages within the brainstem and cerebellum. Neuron 48, 31-43. doi: 10.1016/j.neuron.2005.08.024

Watanabe, D., Inokawa, H., Hashimoto, K., Suzuki, N., Kano, M., Shigemoto, R., et al. (1998). Ablation of cerebellar Golgi cells disrupts synaptic integration involving GABA inhibition and NMDA receptor activation in motor coordination. Cell 95, 17-27. doi: 10.1016/s0092-8674(00)81779-1

Weisheit, G., Gliem, M., Endl, E., Pfeffer, P. L., Busslinger, M., and Schilling, K. (2006). Postnatal development of the murine cerebellar cortex: formation and early dispersal of basket, stellate and Golgi neurons. Eur. J. Neurosci. 24, 466-478. doi: 10.1111/j.1460-9568.2006.04915.x

West-Mays, J. A., Zhang, J., Nottoli, T., Hagopian-Donaldson, S., Libby, D., Strissel, K. J., et al. (1999). AP- $2 \alpha$ transcription factor is required for early morphogenesis of the lens vesicle. Dev. Biol. 206, 46-62. doi: 10.1006/dbio. 1998.9132

Wonders, C. P., and Anderson, S. A. (2006). The origin and specification of cortical interneurons. Nat. Rev. Neurosci. 7, 687-696. doi: 10.1038/nrn1954

Wulff, P., Schonewille, M., Renzi, M., Viltono, L., Sassoè-Pognetto, M., Badura, A., et al. (2009). Synaptic inhibition of Purkinje cells mediates consolidation of vestibulo-cerebellar motor learning. Nat. Neurosci. 12, 1042-1049. doi: 10.1038/nn.2348

Yamada, M., Seto, Y., Taya, S., Owa, T., Inoue, Y. U., Inoue, T., et al. (2014). Specification of spatial identities of cerebellar neuron progenitors by ptfla and atoh1 for proper production of GABAergic and glutamatergic neurons. J. Neurosci. 34, 4786-4800. doi: 10.1523/JNEUROSCI.272213.2014

Yamanaka, H., Yanagawa, Y., and Obata, K. (2004). Development of stellate and basket cells and their apoptosis in mouse cerebellar cortex. Neurosci. Res. 50, 13-22. doi: 10.1016/j.neures.2004.06.008

Zhang, L., and Goldman, J. E. (1996). Generation of cerebellar interneurons from dividing progenitors in white matter. Neuron 16, 47-54. doi: 10.1016/s08966273(00)80022-7

Zhang, J., Hagopian-Donaldson, S., Serbedzija, G., Elsemore, J., PlehnDujowich, D., McMahon, A. P., et al. (1996). Neural tube, skeletal and body wall defects in mice lacking transcription factor AP-2. Nature 381, 238-241. doi: $10.1038 / 381238 \mathrm{a} 0$

Zhao, Y., Kwan, K. M., Mailloux, C. M., Lee, W. K., Grinberg, A., Wurst, W., et al. (2007). LIM-homeodomain proteins Lhx1 and Lhx5, and their cofactor Ldb1, control Purkinje cell differentiation in the developing cerebellum. Proc. Natl. Acad. Sci. U S A 104, 13182-13186. doi: 10.1073/pnas.0705464104

Zordan, P., Croci, L., Hawkes, R., and Consalez, G. G. (2008). Comparative analysis of proneural gene expression in the embryonic cerebellum. Dev. Dyn. 237, 1726-1735. doi: 10.1002/dvdy.21571

Conflict of Interest Statement: The authors declare that the research was conducted in the absence of any commercial or financial relationships that could be construed as a potential conflict of interest.

Copyright (c) 2017 Zainolabidin, Kamath, Thanawalla and Chen. This is an open-access article distributed under the terms of the Creative Commons Attribution License (CC BY). The use, distribution or reproduction in other forums is permitted, provided the original author(s) or licensor are credited and that the original publication in this journal is cited, in accordance with accepted academic practice. No use, distribution or reproduction is permitted which does not comply with these terms. 